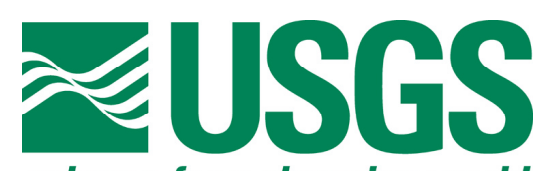

science for a changing world

\title{
Historical Seismicity in the South San Francisco Bay Region
}

By William H. Bakun'

Open-File Report 2008-1151, v. 1.1

2008, revised 2009

${ }^{1}$ Menlo Park, Calif. 


\title{
U.S. Department of the Interior DIRK KEMPTHORNE, Secretary
}

\section{U.S. Geological Survey \\ Mark D. Myers, Director}

\section{U.S. Geological Survey, Reston, Virginia 2008}

Revised 2009

\author{
For product and ordering information: \\ World Wide Web: http://www.usgs.gov/pubprod \\ Telephone: 1-888-ASK-USGS
}

For more information on the USGS-the Federal source for science about the Earth, its natural and living resources, natural hazards, and the environment: World Wide Web: http://www.usgs.gov

Telephone: 1-888-ASK-USGS

Suggested citation:

Bakun, William H., 2008, revised 2009, Historical seismicity in the south San Francisco Bay region: U.S. Geological Survey, Open-File Report 2008-1151, v. 1.1

[http://pubs.usgs.gov/of/2008/1151/]

Any use of trade, product, or firm names is for descriptive purposes only and does not imply endorsement by the U.S. Government.

Although this report is in the public domain, permission must be secured from the individual copyright owners to reproduce any copyrighted material contained within this report. 


\section{Summary}

Locations (intensity centers) and moment magnitude $\mathbf{M}$ for 24 earthquakes (1858-1911) in the southern San Francisco Bay area are estimated from Modified Mercalli intensity (MMI) assignments. The uncertainties in location and $\mathbf{M}$ are generally large because there are few MMI assignments available. Preferred locations are selected to be consistent with a simple model (Oppenheimer et al., 2008; Bakun et $a l ., 2008)$ for seismic activity on the central and southern Calaveras fault. Significant seismic activity can be explained by repetitive failure of the same fault areas in nearly identical earthquakes.

Significant earthquake activity occurred on both east- and west-Bay faults in the ten or so years before the 1868 eastBay earthquake and before the1906 and 1989 west-Bay earthquakes. 


\section{Introduction}

The 31 October 2007 M5.4 Alum Rock earthquake provided strong support for Oppenheimer et al.'s (1990) model for seismicity on the central and southern Calaveras fault. Nearly identical waveforms for the 2007 event and the 5 September $1955 \mathrm{M}_{\mathrm{L}} 5.5$ earthquake (Oppenheimer et al., 2008) showed that both events occurred on Oppenheimer et al.'s (1990) Zone V on the central Calaveras fault. Oppenheimer et al. (1990) had shown that waveforms for the 26 October $1943 \mathrm{M}_{\mathrm{L}} 4.9$ and the 13 June 1988 M 5.0 earthquakes were also nearly identical and that both of these events were located on a patch of the central Calaveras fault which they labeled Zone IV. These recurring $\mathbf{M}$ 5-6 earthquakes suggest a simple model for seismic activity on the central and southern Calaveras fault. Significant seismic activity can be explained by repetitive failure of the same fault areas in nearly identical earthquakes. This report presents analyses of seismic intensity data necessary to address the question "Is the pre-instrumental seismicity in the region consistent with this simple model of seismicity?" This question is addressed directly by Oppenheimer et al. (2008b)

I use Bakun's (1999) list of significant San Francisco Bay region earthquakes, his Table 2 (updated to include events since 1999), as the starting point of this study. The locations and M given here are consistent with Bakun's (1999) analysis. The uncertainties in location are often large and Bakun (1999) sometimes chose not to list a preferred location or an intensity center for poorly located events. This report provides details of location and $\mathbf{M}$ and their uncertainties that were not given by Bakun (1999). In particular, the feasibility of location of historical earthquakes on Oppenheimer et al.'s (1990) Calaveras fault Zones I-VI is addressed.

My preferred locations in Table 1 are the epicenters for post-1911 earthquakes and my best guess for the epicenters of the pre-instrumental events. The intensity centers provided by the analysis are used for events with sufficient MMI assignments to reasonably constrain the intensity center locations. The intensity centers, however, are not good estimates of location for many of the events studied here. As an example, consider the earthquake that occurred on 30 March 1883 shown in Figure 13. The maximum intensities were assigned at a cluster of communities straddling the San Andreas Fault east of Monterey Bay. The earthquake generally was not felt at communities in San Luis Obispo County to the south, closer to the intensity center 
$\left(36.1^{\circ} \mathrm{N}, 122.8^{\circ} \mathrm{W}\right) \cdot \mathrm{M}_{\mathrm{I}}$ at the intensity center is 7.1 . A magnitude 7 earthquake in 1883 near the intensity center would have been felt all along the central California coast. For this earthquake, the intensity center is a computational artifact, and it should be ignored. MMI assignments at distant sites are necessary to constrain the location. A few MMI III assignments, if available, would constrain the intensity center to the region of the maximum MMI. Lacking those MMI assignments, the algorithm provides an implausible intensity center. My preferred location, on the San Andreas Fault, near the cluster on maximum MMI, honors the available data and ignores the implausible intensity center. I do not list implausible intensity centers in this report lest the casual reader mistakenly adopt these artifacts as useful information.

My preferred locations for some earthquakes are selected to be consistent with Oppenheimer et al.'s (2008b) model of repetitive failure of the same Calaveras fault areas in nearly identical earthquakes. Specifically, my preferred locations for earthquakes on 26 November 1858 (\#1) and 2 January 1891 (\#17) are in Oppenheimer's (1990) Zone V. Similarly, my preferred location for the earthquake on 20 June 1897 (\#19) is in Oppenheimer's (1990) Zone II. Other locations are possible for these three events. Oppenheimer et al.'s (2008b) model can be extended through the pre-instruimental period with these preferred locations. My preferred locations for the other preinstrumental events are elsewhere, i.e., not on the Calaveras fault.

\section{Instrumental Earthquakes (1911 - 2008)}

Earthquakes in the southern San Francisco Bay region that were recorded on seismographs (Table 1, Part b) are taken from Oppenheimer et al. (1990) and Oppenheimer et al. (2008). The 9 March $1949 \mathrm{M}_{\mathrm{L}} 5.2$ event and the 6 August 1979 M 5.9 Coyote Lake earthquake occurred on Zones I and II, respectively. The 1 July 1911 M 6.2 and the 24 April 1984 M 6.2 Morgan Hill earthquakes occurred on Zone III. The 26 October $1943 \mathrm{M}_{\mathrm{L}} 4.9$ and the 13 June 1988 M 5.0 earthquakes occurred on Zone IV. The 5 September $1955 \mathrm{M}_{\mathrm{L}} 5.5$ and the 31 October 2007 M 5.4 earthquakes occurred on Zone V. No earthquakes are known to have occurred in Zone VI. Historical (pre-1911) earthquakes in the region are listed in Table 1, Part a. 


\section{Intensity Data}

Almost all of the MMI assignments used here are listed in Bakun (1998). J. Boatwright and $\mathrm{H}$. Bundock (personal communication, 2008) have compiled more-extensive sets of MMI assignments for the 4 July 1861 northern Calaveras fault earthquake and for the 21 October 1868 Hayward fault earthquake. Their MMI assignments are used in the analysis of the 1861 event. Toppozada et al. 's (1981) MMI assignments and Boatwright and Bundock's (personal communication, 2008) MMI assignments are used for independent analyses of the 1868 earthquake.

\section{Analysis of Intensity Data}

Following Bakun (1999), I estimate M from individual intensity observations for a trial epicenter using

$$
\mathrm{M}_{\mathrm{I}}=\operatorname{mean}\left(\mathrm{M}_{\mathrm{i}}\right) \text {, }
$$

where

$$
\mathrm{M}_{\mathrm{i}}=\left\{\left(\mathrm{MMI}_{\mathrm{i}}-\delta \mathrm{MMI}_{\mathrm{i}}\right)+3.29+0.0206 \Delta_{\mathrm{h}, \mathrm{i}}\right\} / 1.68
$$

$\mathrm{MMI}_{\mathrm{i}}, \delta \mathrm{MMI}_{\mathrm{i}}$ and $\Delta_{\mathrm{h}, \mathrm{i}}$ are the MMI value, the site correction and the hypocentral distance, respectively, at site i. A depth of $10 \mathrm{~km}$ is assumed. The $\delta \mathrm{MMI}$ are listed in Bakun (1998). $\delta M M I_{i}$ is zero if a site correction is not available.

I find the misfit for each trial epicenter from

$$
\operatorname{rms}\left[M_{I}\right]=\left[r m s\left(M_{I}-M_{i}\right)-\operatorname{rms}_{0}\left(M_{I}-M_{i}\right)\right] \text {, }
$$

where rms $\left(M_{I}-M_{i}\right)=\left\{{ }_{i}\left[W_{i}\left(M_{I}-M_{i}\right)\right]^{2} /{ }_{i} W_{i}{ }^{2}\right\}^{1 / 2}, \operatorname{rms}_{0}\left(M_{I}-M_{i}\right)$ is the minimum rms $\left(M_{I}-M_{i}\right)$ over the grid of trial epicenters, and $\mathrm{W}_{\mathrm{i}}$ is Bakun and Wentworth's (1997) distance weighting function:

$$
\mathrm{W}_{\mathrm{i}}= \begin{cases}0.1+\cos \left[\left(\Delta_{\mathrm{i}} / 150\right)(/ 2)\right] & \text { for } \Delta_{\mathrm{i}}<150 \mathrm{~km} \\ 0.1 & \text { for } \Delta_{\mathrm{i}} \geq 150 \mathrm{~km} .\end{cases}
$$

The intensity center is the trial source location for which $r m s\left[M_{I}\right]$ is minimum (Bakun, 1999). 
The $\mathrm{rms}\left[\mathrm{M}_{\mathrm{I}}\right]$ contours provide a basis for identifying regions of likely epicenter location. The $\mathrm{rms}\left[\mathrm{M}_{\mathrm{I}}\right]$ contours bound the epicentral region. Bakun and Wentworth (1997) associated rms contour values with confidence levels that the epicenter was within the contour, as tabulated in the corrected Table 5b of Bakun and Wentworth (1999). $\mathrm{M}_{\mathrm{I}}$ at trial locations within the appropriate confidence-level contours is the best estimate of $\mathbf{M}$ for these source locations.

\section{Analysis of MMI for 24 Historical Earthquakes (1858-1911)}

26 November 1858. MMI can be assigned at seven of the 16 localities for which felt reports (Toppozada et al., 1981) are available. The maximum MMI was assigned at San Jose where brick walls were cracked and chimneys thrown down. Zones III-VI on the Calaveras fault are within the $67 \%$ confidence contour for location (Figure 1). $M_{I}$ is 6.2 for zones IV and V. The preferred location is in zone $\mathrm{V}$ at the epicenter of the 31 Oct 2007 event.

4 July 1861. MMI have been assigned at 13 sites (J. Boatwright and H. Bundock, personal communication, 2008). The maximum intensity is VIII-IX in Amador Valley. MMI VII-VIII intensities were assigned at residences in San Ramon Valley near the location of reported fissures along the Calaveras fault near Dublin (Toppozada et al., 1981) and the intensity center (Figure 2). The intensity center, the preferred location, is located near the trace of the northern Calaveras fault. $M_{I}$ is 5.9.

26 February 1864. MMI can be assigned at five of the 11 localities for which felt reports (Toppozada et al., 1981) are available. The maximum assigned MMI VI was assigned at Monterey, San Francisco, San Jose, and Watsonville. Zones I-VI on the Calaveras fault are within the $67 \%$ confidence contour for location (Figure 3). Although a location on the Calaveras fault is possible, the maximum MMI at Monterey, San Jose and Watsonville are more consistent with a west bay fault. A location near the San Andreas Fault is preferred. $M_{I}$ is 5.6.

5 March 1864. MMI can be assigned at eight of the 19 localities for which felt reports (Toppozada et al., 1981) are available. The maximum MMI VI was assigned at San Francisco, San Jose, and Stockton. Zones I-VI on the Calaveras fault are within the 67\% confidence contour for location (Figure 4). $\mathrm{M}_{\mathrm{I}}$ is 5.3 for zones IV-VI. A location near the Mission siesmic trend is preferred. 
21 May 1864. MMI can be assigned at four of the 10 localities for which felt reports (Toppozada et al., 1981) are available. The maximum MMI VI was assigned at San Francisco and San Jose. Zones I-VI on the Calaveras fault are within the $67 \%$ confidence contour for location but a location near the San Andreas Fault, at the intensity center, is preferred (Figure 5). $M_{I}$ is 5.6.

24 May 1865. MMI can be assigned at four of the 7 localities for which felt reports (Toppozada et al., 1981) are available. The maximum MMI VI was assigned at San Juan Bautista. Zones I-III on the Calaveras fault are within the $67 \%$ confidence contour for location, the maximum MMI at San Juan Bautista is more consistent with a west bay fault (Figure 6). $M_{I}$ is 5.9 .

8 October 1865. MMI can be assigned at 27 localities for which felt reports (Toppozada et al., 1981) are available. Bakun's (1999) analysis is adopted. The intensity center, the preferred location, is near the Berrocal fault (Figure 7). $M_{I}$ is 6.5.

26 March 1866. MMI can be assigned at six of the 12 localities for which felt reports (Toppozada et al., 1981) are available. The maximum MMI VII was assigned at Gilroy. Zones I-II on the Calaveras fault are within the $67 \%$ confidence contour for location, but a location closer to the San Andreas Fault is preferred (Figure 8). $M_{I}$ is 5.6.

21 October 1868. MMI were assigned at 70 localities by Toppozada et al. (1981). Bakun's (1999) analysis of that data yields an intensity center on the Hayward fault and $M_{I}$ is 6.8 (Figure 9a). J. Boatwright and H. Bundock (personal communication, 2008) have reexamined the accounts for the 1868 earthquake and have assigned MMI at 133 sites. The intensity center based on these MMI assignments is also on the trace of the Hayward fault, but farther south near the intersection of the Hayward fault and Mission seismic trend (Figure 9b). $M_{I}$ is 6.5. The preferred location is at the intensity center in Figure 9a.

17 February 1870. MMI can be assigned at ten of the 21 localities for which felt reports (Toppozada et al., 1981) are available. The maximum MMI VII was assigned at Los Gatos and Santa Cruz. Zones III-VI on the Calaveras fault are within the $67 \%$ confidence contour for location, but a location near the 8 October 1865 epicenter is perhaps more likely (Figure 10). The preferred location is at the intensity center. $M_{I}$ is 5.7. 
2 April 1870. MMI can be assigned at nine of the 14 localities for which felt reports (Toppozada et al., 1981) are available. The maximum MMI VI was assigned at Oakland, San Leandro, San Francisco and Petaluma. The intensity center is on the 1868 Hayward fault rupture (Figure 11). The preferred location is at the intensity center. $M_{I}$ is 5.6.

6 March 1882. MMI can be assigned at nine of the 18 localities for which felt reports (Toppozada et al., 1981) are available. The maximum MMI VI was assigned at Salinas, Hollister, and Santa Cruz. The preferred location is on the San Andreas Fault (Figure 12). $M_{I}$ is 5.0.

30 March 1883. MMI can be assigned at nine of the 25 localities for which felt reports (Toppozada et al., 1981) are available. The maximum MMI VII was assigned at Old Gilroy and Sargents where chimneys were thrown down. The preferred location is on the San Andreas Fault (Figure 13). $M_{I}$ is 5.9.

17 September 1888. MMI can be assigned at four sites with MM V at Gilroy, San Jose, and Santa Cruz, suggesting a west bay location. The preferred location is on the San Andreas Fault (Figure 14). $M_{I}$ is 5.9.

31 July 1889. MMI can be assigned at seventeen of the 41 localities for which felt reports (Toppozada et al., 1981) are available. The maximum MMI VII was assigned at San Leandro and West Oakland where chimneys were thrown down. The intensity center is near the 1868 Hayward fault rupture (Figure 15). The preferred location is at the intensity center. $\mathrm{M}_{\mathrm{I}}$ is 5.6.

24 April 1890. There are $29 \mathrm{MMI}$ available for this event. Cracks were observed on the San Andreas Fault trace near the Pajaro River. The maximum intensity was VIII at Corralitos, Green Valley, Pajaro, San Juan Bautista, and Sargents (Toppozada et al., 1981). The preferred location is on the San Andreas Fault near the intensity center (Figure 16). $\mathrm{M}_{\mathrm{I}}$ is 6.3 .

2 January 1891. MMI can be assigned at sixteen of the 31 localities for which felt reports (Toppozada et al., 1981) are available. The maximum MMI VI was assigned at Alameda, Mt. Hamilton, San Jose, Boulder Creek, and Santa Cruz. Zones II-VI on the Calaveras fault are within the 67\% confidence contour for location (Figure 17). $\mathrm{M}_{\mathrm{I}}$ is 5.7. The preferred location is in zone $\mathrm{V}$ at the epicenter of the 31 Oct 2007 event. 
13 November 1892. MMI can be assigned at eleven of the 28 localities for which felt reports (Toppozada et al., 1981) are available. The maximum MMI VII was assigned at Hollister and Sargents where chimneys were thrown down. The preferred location is on the San Andreas Fault (Figure 18). $\mathrm{M}_{\mathrm{I}}$ is 5.8.

20 June 1897. MMI can be assigned at 39 localities for which felt reports (Toppozada et al., 1981) are available. The maximum MMI VIII was assigned at Mission San Carlos, Gilroy, and San Felipe. Fissures were reported on the Pacheco Pass road near San Felipe for the M6.3 1897 event (Toppozada et al., 1981). The trace of the Calaveras fault crosses the Pacheco Pass Road near San Felipe, which is located near the north end of zone I. Surface slip during the 1979 Coyote Lake earthquake was observed near San Felipe (Reasenberg and Ellsworth, 1982). McClellan and Hay (1990) reported triggered right-lateral slip on the Calaveras fault at Highway 152 near San Felipe Lake at the time of the 1989 Loma Prieta earthquake. Fresh northwest-striking cracks, observed at Highway 152 after the 1984 Morgan Hill earthquake, were interpreted as triggered slip (Galehouse and Brown, 1987; Harms et al., 1987). The fissures noted in 1897 in the same area may also have been triggered slip. Bakun's (1999) analysis is assumed. Zones I-III on the Calaveras fault are within the $67 \%$ confidence contour for location (Figure 19). $M_{I}$ is 6.3. The preferred location is in zone II.

6 July 1899. MMI can be assigned at twelve localities for which felt reports (Toppozada et al., 1981) are available. The pattern of reports is anomalous in that high intensities were reported at Pleasanton, Alameda County, and near Watsonville but high intensities were not reported at sites between Pleasanton and Watsonville (Toppozada et al., 1981). Townley and Allen (1939) suggested that two earthquakes occurred -a larger event near Watsonville and a smaller earthquake near Pleasanton. I discount here the account at Pleasanton. Zones I and II on the Calaveras fault are within the $67 \%$ confidence contour for location, but a location closer to the San Andreas Fault is preferred (Figure 20). $M_{I}$ is 5.7 .

30 April 1899. MMI can be assigned at 15 localities for which felt reports (Toppozada et al., 1981) are available. The maximum MMI VII was assigned at Green Valley and Watsonville where chimneys were thrown down. The preferred location is on the San Andreas Fault (Figure 21). $\mathrm{M}_{\mathrm{I}}$ is 5.8 . 
11 June 1903. MMI can be assigned at 26 localities for which felt reports (Toppozada et al., 1981) are available. Zones II-VI on the Calaveras fault are within the $67 \%$ confidence contour for location (Figure 22). $\mathrm{M}_{\mathrm{I}}$ is 6.1. The preferred location is at the intensity center.

3 August 1903. MMI can be assigned at 22 localities for which felt reports (Toppozada et al., 1981) are available. Zones III-VI on the Calaveras fault are within the 67\% confidence contour for location (Figure 23). $\mathrm{M}_{\mathrm{I}}$ is 6.1. The preferred location is at the intensity center.

1 July 1911. MMI can be assigned at 31 localities for which felt reports (Toppozada et al., 1981) are available. Bakun's (1999) analysis is assumed. Zones III-VI on the Calaveras fault are within the $67 \%$ confidence contour for location (Figure 24).

Oppenheimer et al. (1990) argue that the 1911 event occurred on Zone III. $\mathrm{M}_{\mathrm{I}}$ is 6.2. The preferred location is in zone III at the epicenter of the 1984 Morgan Hill earthquake.

\section{Conclusions}

The preferred locations and $\mathbf{M}$ for the historical earthquakes are summarized in Table 1 and Figure 25. Five of the 11 earthquakes in the 1850-1870 period apparently were on east Bay faults; the remaining six events were on west Bay faults. Seven of the 12 earthquakes in the 25 years before the 1906 earthquake and five of the 6 earthquakes in the 25 years before the 1989 Loma Prieta earthquake occurred on east Bay faults. That is, significant seismicity in the west Bay apparently preceded the large 1868 east Bay event and significant seismicity in the east Bay apparently preceded the large 1906 and 1989 west Bay events.

\section{References}

Bakun, W.H. (1998). Modified Mercalli intensities for some recent California earthquakes and historic San Francisco Bay region earthquakes, U. S. Geol. Surv Open-file Report 98-584, 175 p.

Bakun, W.H. (1999). Seismic activity of the San Francisco Bay region, Bull. Seism. Soc. Am. 89, 764-784.

Bakun, W. H., and C. M. Wentworth (1997). Estimating location and magnitude from seismic intensity data, Bull. Seism. Soc. Amer. 87, 1502-1521. 
Bakun, W. H. and C. M. Wentworth (1999). Erratum to Estimating earthquake location and magnitude from seismic intensity data, Bull. Seismol. Soc. Am. 89, 557.

Bakun, W.H., D. Oppenheimer, J. Boatwright, and R. Simpson (2008). Earthquakes on the Central and Southern Calaveras fault and Earthquake Forecasts: Part II, 18501910 (abstract), Seismol. Res. Lett., vol. 79, p. 343.

Galehouse, J. S., and B. D. Brown (1979). Surface displacement near Hollister, California, in Hoose, S, N., (Ed.), The Morgan Hill, California, earthquake of April 24, 1984, U. S. Geol. Surv. Bull. 1639, 69-72.

Harms, K. K., M. M. Clark, and others (1987). The search for surface faulting, in Hoose, S, N., (Ed.), The Morgan Hill, California, earthquake of April 24, 1984, U. S. Geol. Surv. Bull. 1639, 61-68.

Jennings, C. W. (1994). Fault activity map of California and adjacent areas, California Geological Data Map Series, California Division of Mines and Geology, map no. 6.

McClellan, P. H., and E. A. Hay (1989). Triggered slip on the Calaveras fault during the magnitude 7.1 Loma Prieta, California, earthquake, Geoph. Res. Lett. 17, 20272030.

Oppenheimer, D. H., W. H. Bakun, A. G. Lindh (1990). Slip partitioning of the Calaveras fault, California, and prospects for future earthquakes, J. Geophys. Res. 95, 8483-8498.

Oppenheimer, D., W. Bakun, R. Uhrhammer, J. Boatwright, and R. Simpson (2008a). Earthquakes on the Central and Southern Calaveras fault and Earthquake Forecasts: Part I, 1910-Present (abstract), Seismol. Res. Lett., vol. 79, p. 342.

Oppenheimer, D., W. Bakun, R. Uhrhammer, J. Boatwright, and R. Simpson (2008b). The 2007 M5.4 Alum Rock Earthquake: Implications for Future Earthquakes on the Central and Southern Calaveras Fault, J. Geophys. Res. in preparation Reasenberg, P., and W. L. Ellsworth (1982). Aftershocks of the Coyote lake, California, earthquake of August 6, 1979; a detailed study, J. Geophys. Res. 87, 10,63710,665 .

Toppozada, T. R., C. R. Real and D. L. Parke (1981). Preparation of isoseismal maps and summaries of reported effects for Pre-1900 California earthquakes, Calif. Div. Mines and Geol. Open-File Rept. 81-11 SAC, 182 pp. 
\#

Date

Preferred Location

\begin{tabular}{|c|c|}
\hline $\begin{array}{c}\text { M @ } \\
\text { Preferred } \\
\text { Location }\end{array}$ & $\begin{array}{c}\text { M }(95 \% \\
\text { Conf. } \\
\text { Ranae) }\end{array}$ \\
\hline
\end{tabular}

$37.4^{\circ} \mathrm{N}, 121.8^{\circ} \mathrm{W}$

$37.7^{\circ} \mathrm{N}, 121.9^{\circ} \mathrm{W}$

$37.0^{\circ} \mathrm{N}, 121.8^{\circ} \mathrm{W}$

$37.5^{\circ} \mathrm{N}, 121.9^{\circ} \mathrm{W}$

$37.2^{\circ} \mathrm{N}, 122.0^{\circ} \mathrm{W}$

$37.0^{\circ} \mathrm{N}, 121.7^{\circ} \mathrm{W}$

$37.2^{\circ} \mathrm{N}, 121.9^{\circ} \mathrm{W}$

$36.9^{\circ} \mathrm{N}, 121.7^{\circ} \mathrm{W}$

$37.7^{\circ} \mathrm{N}, 122.1^{\circ} \mathrm{W}$

$37.2^{\circ} \mathrm{N}, 122.0^{\circ} \mathrm{W}$

$37.8^{\circ} \mathrm{N}, 122.2^{\circ} \mathrm{W}$

$36.8^{\circ} \mathrm{N}, 121.6^{\circ} \mathrm{W}$

$36.9^{\circ} \mathrm{N}, 121.7^{\circ} \mathrm{W}$

$37.0^{\circ} \mathrm{N}, 121.7^{\circ} \mathrm{W}$

$37.7^{\circ} \mathrm{N}, 122.2^{\circ} \mathrm{W}$

$37.0^{\circ} \mathrm{N}, 121.8^{\circ} \mathrm{W}$

$37.4^{\circ} \mathrm{N}, 121.8^{\circ} \mathrm{W}$

$36.9^{\circ} \mathrm{N}, 121.7^{\circ} \mathrm{W}$

$37.1^{\circ} \mathrm{N}, 121.5^{\circ} \mathrm{W}$

$36.9^{\circ} \mathrm{N}, 121.7^{\circ} \mathrm{W}$

$37.0^{\circ} \mathrm{N}, 121.7^{\circ} \mathrm{W}$

$37.3^{\circ} \mathrm{N}, 121.8^{\circ} \mathrm{W}$

$37.4^{\circ} \mathrm{N}, 121.9^{\circ} \mathrm{W}$

$\begin{array}{lcc}6.2 & 5.7-6.6 & 7 \\ 5.9 & 5.5-6.2 & 13 \\ 5.6 & 5.0-6.1 & 5 \\ 5.3 & 4.8-5.7 & 8 \\ 5.6 & 5.0-6.1 & 4 \\ 5.9 & 5.3-6.4 & 4 \\ 6.5 & 6.2-6.7 & 27 \\ 5.6 & 5.1-6.0 & 6 \\ 6.8 & 6.5-7.0 & 70 \\ 5.7 & 5.3-6.1 & 10 \\ 5.6 & 5.2-6.0 & 9 \\ 5.9 & 5.5-6.3 & 9 \\ 5.9 & 5.5-6.3 & 9 \\ 5.0 & 4.4-5,5 & 4 \\ 5.6 & 5.2-5.9 & 17 \\ 6.3 & 6.0-6.5 & 29 \\ 5.7 & 5.3-6.0 & 16 \\ 5.8 & 5.4-6.2 & 11 \\ 6.3 & 5.7-6.6 & 39 \\ 5.7 & 5.3-6.1 & 11 \\ 5.8 & 5.4-6.1 & 15 \\ 6.1 & 5.9-6.6 & 26 \\ 6.1 & 6.0-6.7 & 22\end{array}$

\section{b) Instrumental Earthquakes}

$\begin{array}{llllcr}24 & 1 \text { July } 1911 & \text { Zone III* } & 37.3^{\circ} \mathrm{N}, 121.7^{\circ} \mathrm{W} & 6.2 & 5.9-6.5 \\ 25 & 26 \text { Oct } 1943 & \text { Zone IV* } & 37.39^{\circ} \mathrm{N}, 121.77^{\circ} \mathrm{W} & \mathrm{M}_{\mathrm{L}} 4.9 & 4.8-5.2 \\ 26 & 9 \text { March } 1949 & \text { Zone I* } & 37.02^{\circ} \mathrm{N}, 121.48^{\circ} \mathrm{W} & \mathrm{M}_{\mathrm{L}} 5.2 & 5.0-5.4 \\ 27 & 5 \text { Sept } 1955 & \text { Zone V* } & 37.43^{\circ} \mathrm{N}, 121.78^{\circ} \mathrm{W} & \mathrm{M}_{\mathrm{L}} 5.5 & 5.3-5.7 \\ 28 & 28 \text { Nov } 1974 & \text { Busch fault } & 36.91^{\circ} \mathrm{N}, 121.48^{\circ} \mathrm{W} & 5.1 & 4.9-5.3 \\ 29 & 6 \text { Aug } 1979 & \text { Zone II* } & 37.10^{\circ} \mathrm{N}, 121.50^{\circ} \mathrm{W} & 5.9 & 5.7-6.1 \\ 30 & 24 \text { April 1984 } & \text { Zone III* } & 37.32^{\circ} \mathrm{N}, 121.70^{\circ} \mathrm{W} & 6.2 & 6.0-6.2 \\ 31 & 31 \text { March 1986 } & \text { Mt. Lewis } & 37.49^{\circ} \mathrm{N}, 121.69^{\circ} \mathrm{W} & 5.7 & 5.5-5.9 \\ 32 & \text { 13 June 1988 } & \text { Zone IV* } & 37.39^{\circ} \mathrm{N}, 121.77^{\circ} \mathrm{W} & 5.0 & 4.8-5.2 \\ 33 & \text { 27 June 1988 } & \text { Lake Elsman } & 37.13^{\circ} \mathrm{N}, 121.88^{\circ} \mathrm{W} & 5.0 & 4.8-5.2 \\ 34 & 18 \text { October 1989 } & \text { Loma Prieta } & 37.04^{\circ} \mathrm{N}, 121.88^{\circ} \mathrm{W} & 6.8 & 6.6-7.0 \\ 35 & 31 \text { Oct } 2007 & \text { Zone V* } & 37.43^{\circ} \mathrm{N}, 121.78^{\circ} \mathrm{W} & 5.4 & 5.2-5.6\end{array}$

* Calaveras fault

\# There is a transcription error in Bakun (1999) where the date of this event is given as 28 June 1882 .

$\S$ Calculated for earthquakes \#1-24 from the number of MMI assignments using Bakun and Wentworth (1999).

The uncertainty for instrumental M is discussed by Bakun (1999) on page 776. 


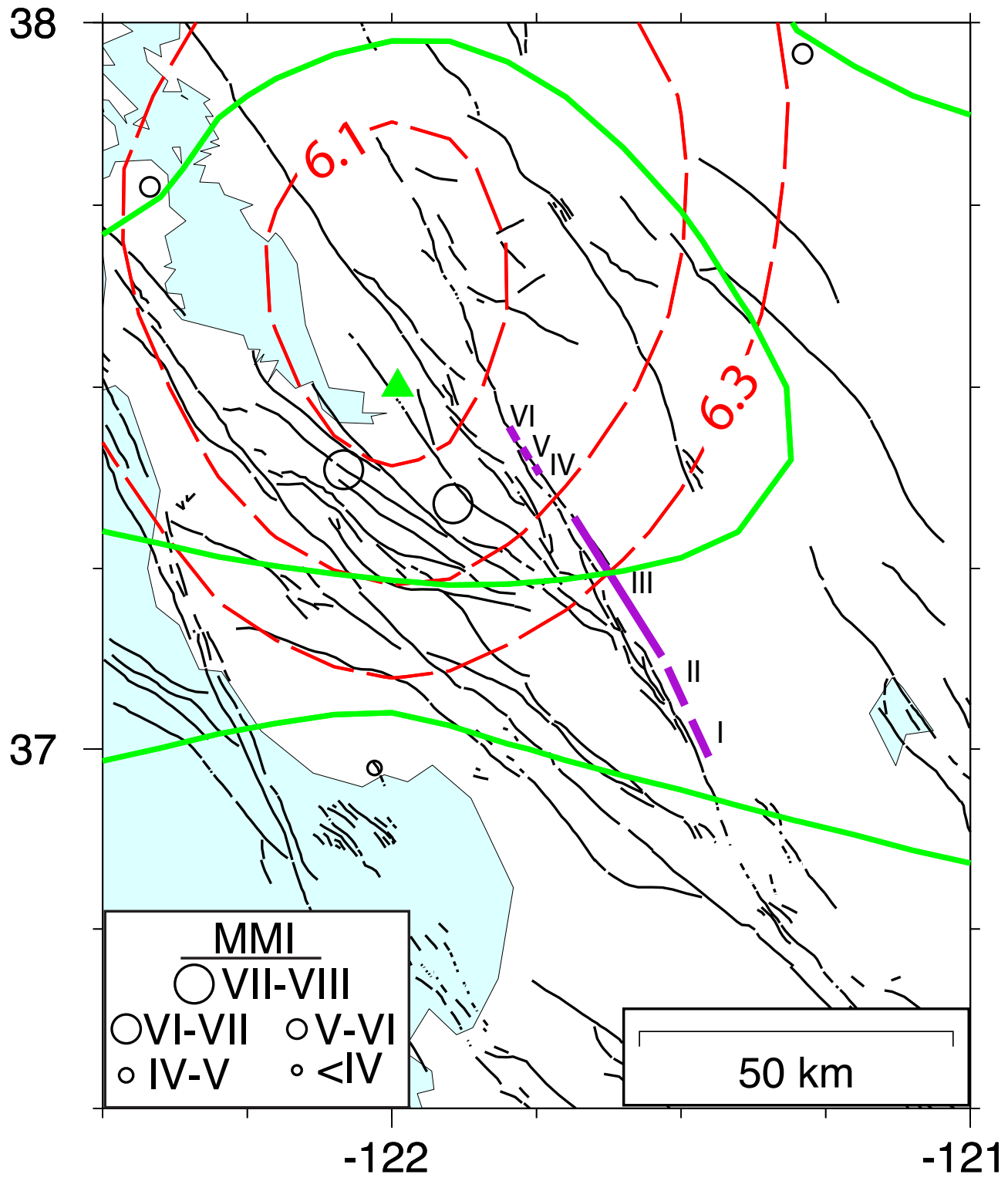

Figure 1. 26 November 1858 earthquake.

(MMI assignment-Site Correction) at 7 sites (some sites may be off the map) are shown as circles relative to Jenning's (1994) active faults (black lines). The contours of $\mathbf{M}_{1}$ (dashed red lines) are the best estimates of $\mathbf{M}$ from the MMI data for assumed epicenters on that contour. The rms $\left[\mathrm{M}_{1}\right]$ contours corresponding to the $67 \%$ (innermost contour) and $95 \%$ confidence contour (outermost contour) for location (Bakun and Wentworth, 1999) are shown as solid green lines. The intensity center (Bakun, 1999) is a green triangle. Locations of Oppenheimer et al.'s (1990) zones I-VI on the central and southern Calaveras fault are shown as violet lines. 


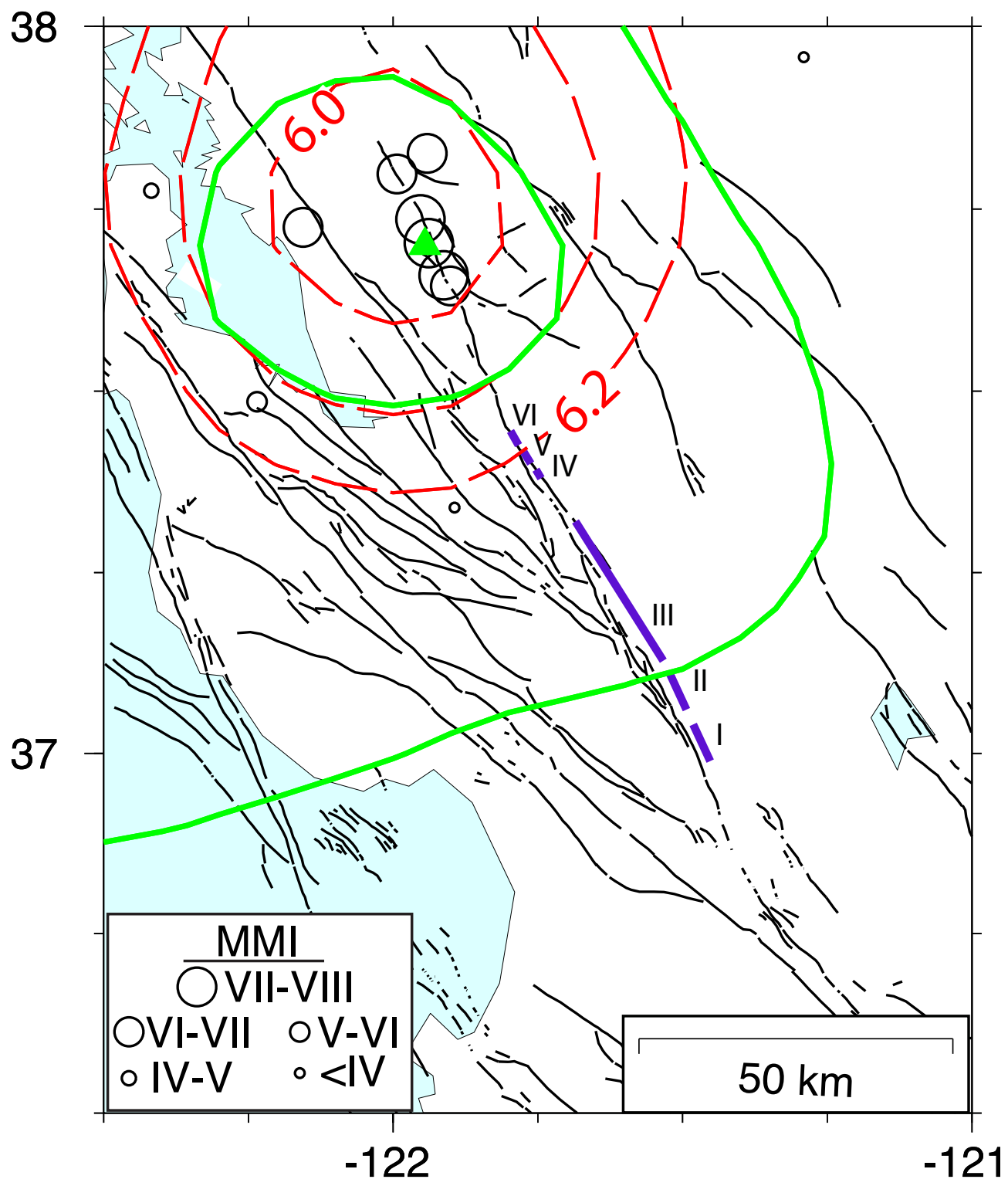

Figure 2.4 July 1861 earthquake.

(MMI assignment-Site Correction) at 13 sites (some sites may be off the map) are shown as circles relative to Jenning's (1994) active faults (black lines). The contours of $M_{\mathbf{I}}$ (dashed red lines) are the best estimates of $\mathbf{M}$ from the MMI data for assumed epicenters on that contour. The rms $\left[\mathrm{M}_{\mathrm{l}}\right]$ contours corresponding to the $67 \%$ (innermost contour) and $95 \%$ confidence contour (outermost contour) for location (Bakun and Wentworth, 1999) are shown as solid green lines. The intensity center (Bakun, 1999) is a green triangle. Locations of Oppenheimer et al.'s (1990) zones I-VI on the central and southern Calaveras fault are shown as violet lines. 


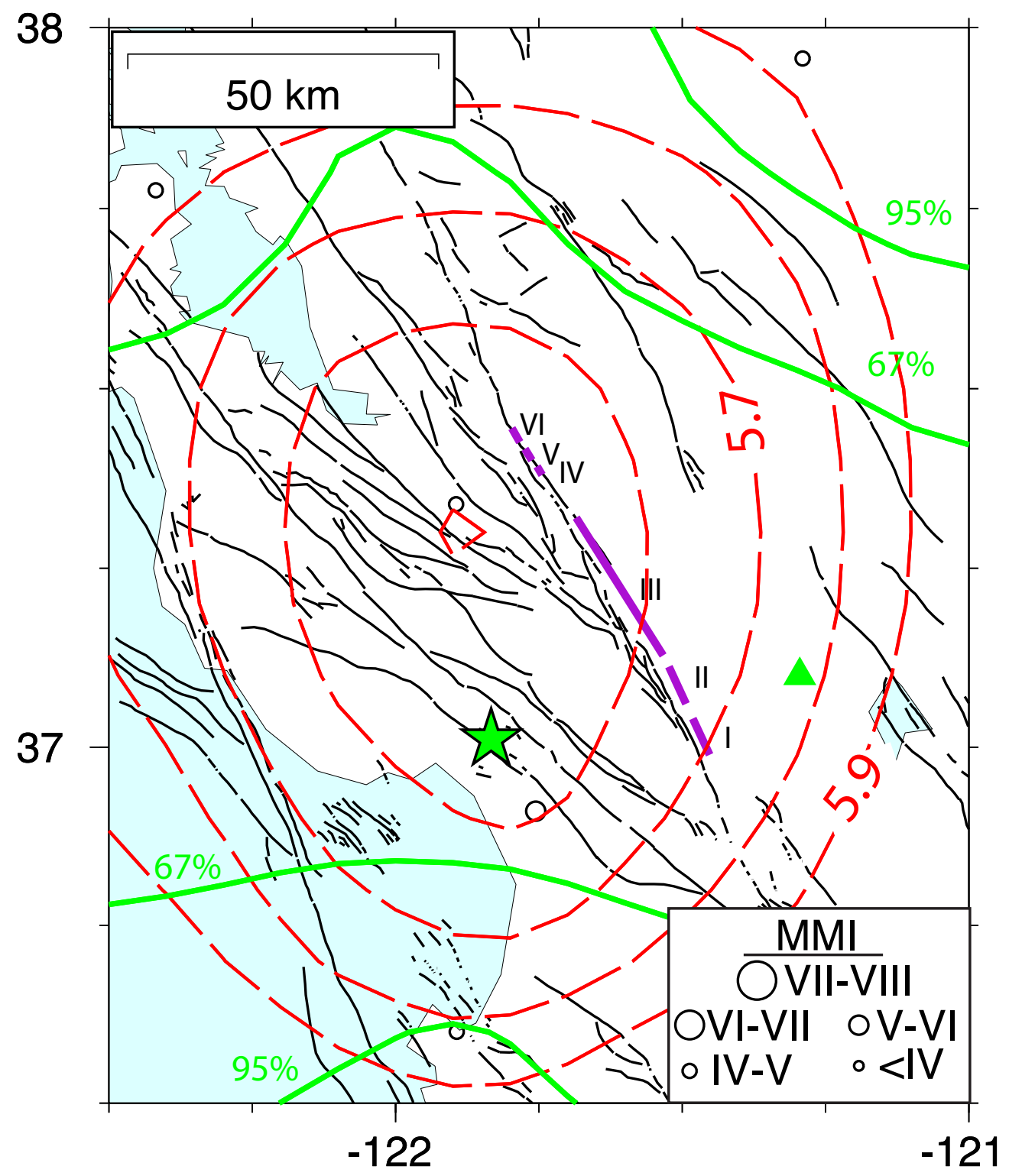

Figure 3. 26 February 1864 earthquake.

(MMI assignment-Site Correction) at 5 sites (some sites may be off the map) are shown as circles relative to Jenning's (1994) active faults (black lines). The contours of $M_{1}$ (dashed red lines) are the best estimates of $\mathbf{M}$ from the MMI data for assumed epicenters on that contour. The rms $\left[\mathrm{M}_{\mathrm{l}}\right]$ contours corresponding to the $67 \%$ (innermost contour) and $95 \%$ confidence contour (outermost contour) for location (Bakun and Wentworth, 1999) are shown as solid green lines. The intensity center (Bakun, 1999) is a green triangle. The preferred location is the green star. Locations of Oppenheimer et al.'s (1990) zones I-VI on the central and southern Calaveras fault are shown as violet lines. 


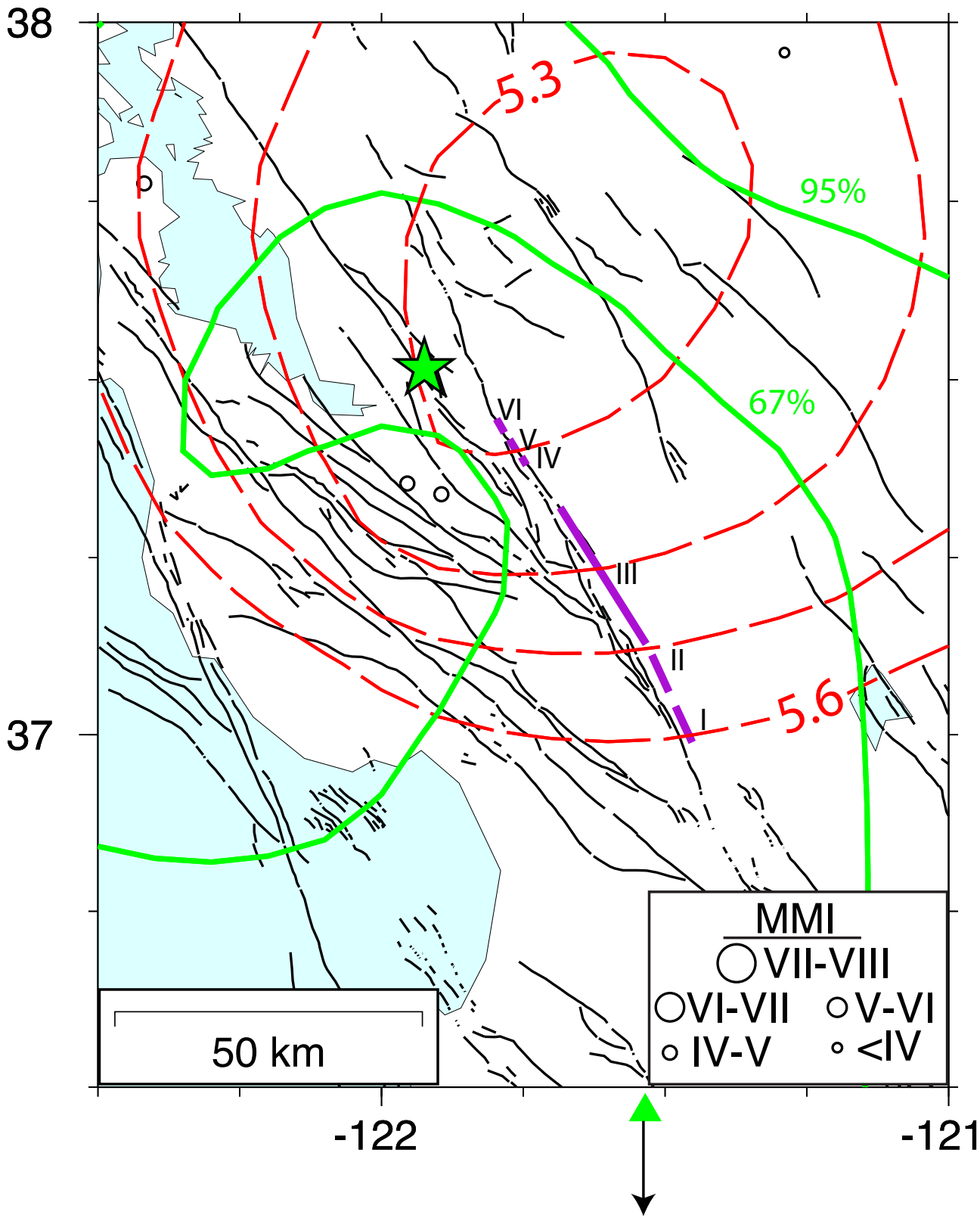

Figure 4. 5 March 1864 earthquake.

(MMI assignment-Site Correction) at 8 sites (some sites may be off the map) are shown as circles relative to Jenning's (1994) active faults (black lines). The contours of $\mathbf{M}_{1}$ (dashed red lines) are the best estimates of $\mathbf{M}$ from the MMI data for assumed epicenters on that contour. The rms $\left[\mathrm{M}_{\mathrm{l}}\right]$ contours corresponding to the $67 \%$ (innermost contour) and $95 \%$ confidence contour (outermost contour) for location (Bakun and Wentworth, 1999) are shown as solid green lines. The intensity center (Bakun, 1999) is a green triangle and id located off the map. The preferred location is the green star. Locations of Oppenheimer et al.'s (1990) zones I-VI on the central and southern Calaveras fault are shown as violet lines. 


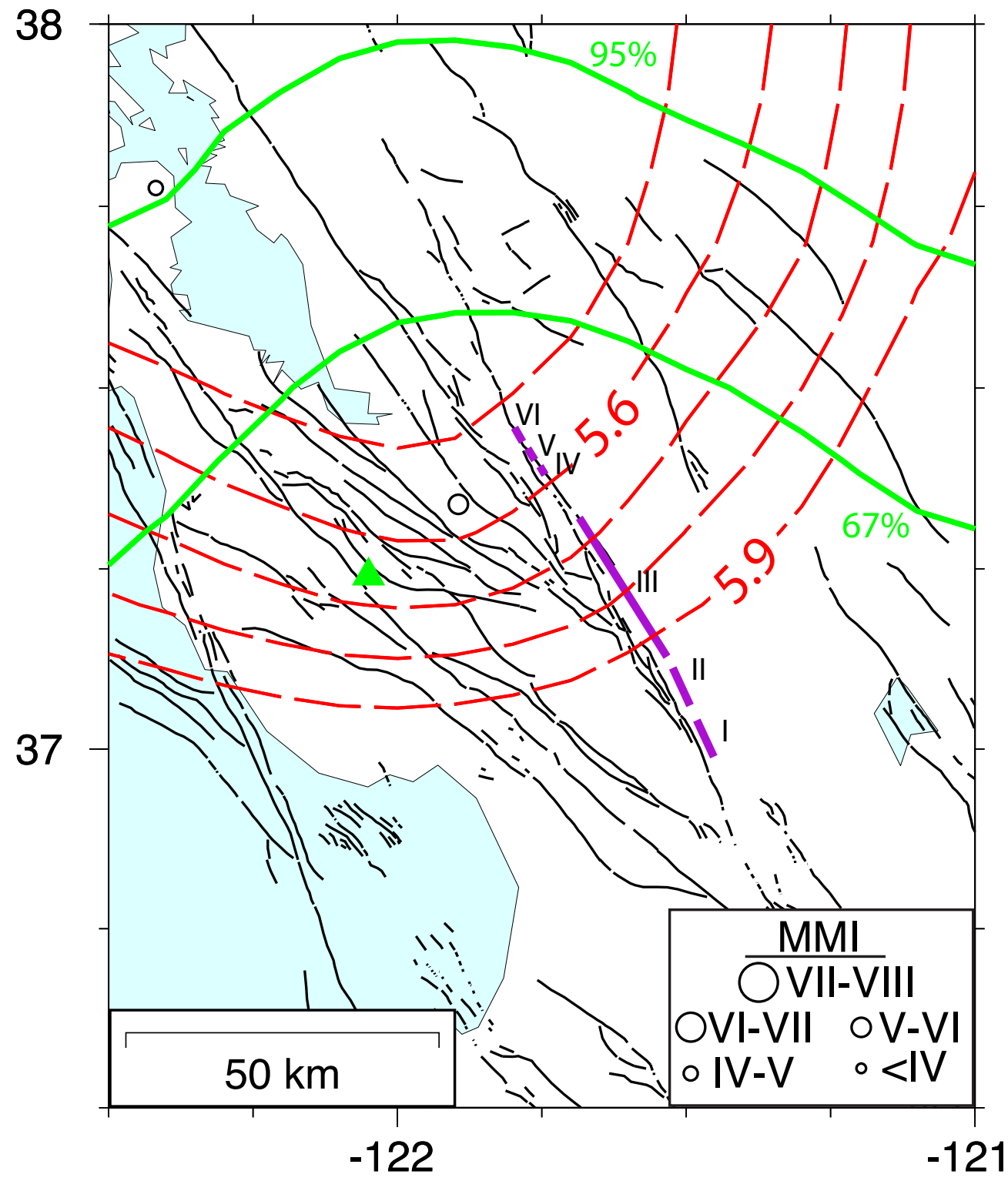

Figure 5. 21 May 1864 earthquake.

(MMI assignment-Site Correction) at 4 sites (some sites may be off the map) are shown as circles relative to Jenning's (1994) active faults (black lines). The contours of $\mathbf{M}_{1}$ (dashed red lines) are the best estimates of $\mathbf{M}$ from the MMI data for assumed epicenters on that contour. The rms $\left[\mathrm{M}_{1}\right]$ contours corresponding to the $67 \%$ (innermost contour) and $95 \%$ confidence contour (outermost contour) for location (Bakun and Wentworth, 1999) are shown as solid green lines. The intensity center (Bakun, 1999) is a green triangle. Locations of Oppenheimer et al.'s (1990) zones I-VI on the central and southern Calaveras fault are shown as violet lines. 


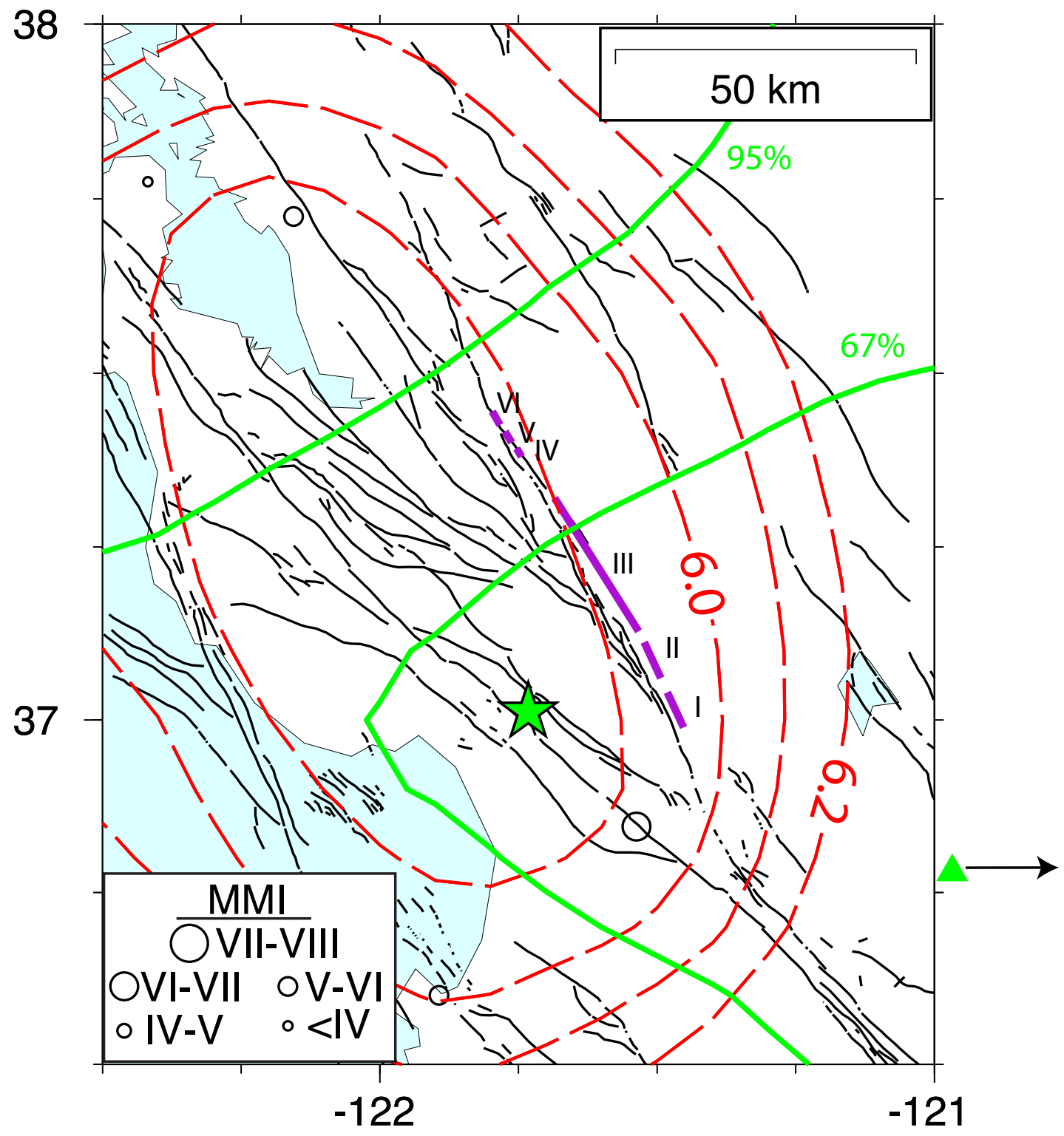

Figure 6. 24 May 1865 earthquake.

(MMl assignment-Site Correction) at 4 sites (some sites may be off the map) are shown as circles relative to Jenning's (1994) active faults (black lines). The contours of $\mathbf{M}_{1}$ (dashed red lines) are the best estimates of $\mathbf{M}$ from the MMI data for assumed epicenters on that contour. The rms $\left[\mathrm{M}_{1}\right]$ contours corresponding to the $67 \%$ (innermost contour) and 95\% confidence contour (outermost contour) for location (Bakun and Wentworth, 1999) are shown as solid green lines. The intensity center (Bakun, 1999) is a green triangle and is located off the map. The preferred location is the green star. Locations of Oppenheimer et al.'s (1990) zones I-VI on the central and southern Calaveras fault are shown as violet lines. 


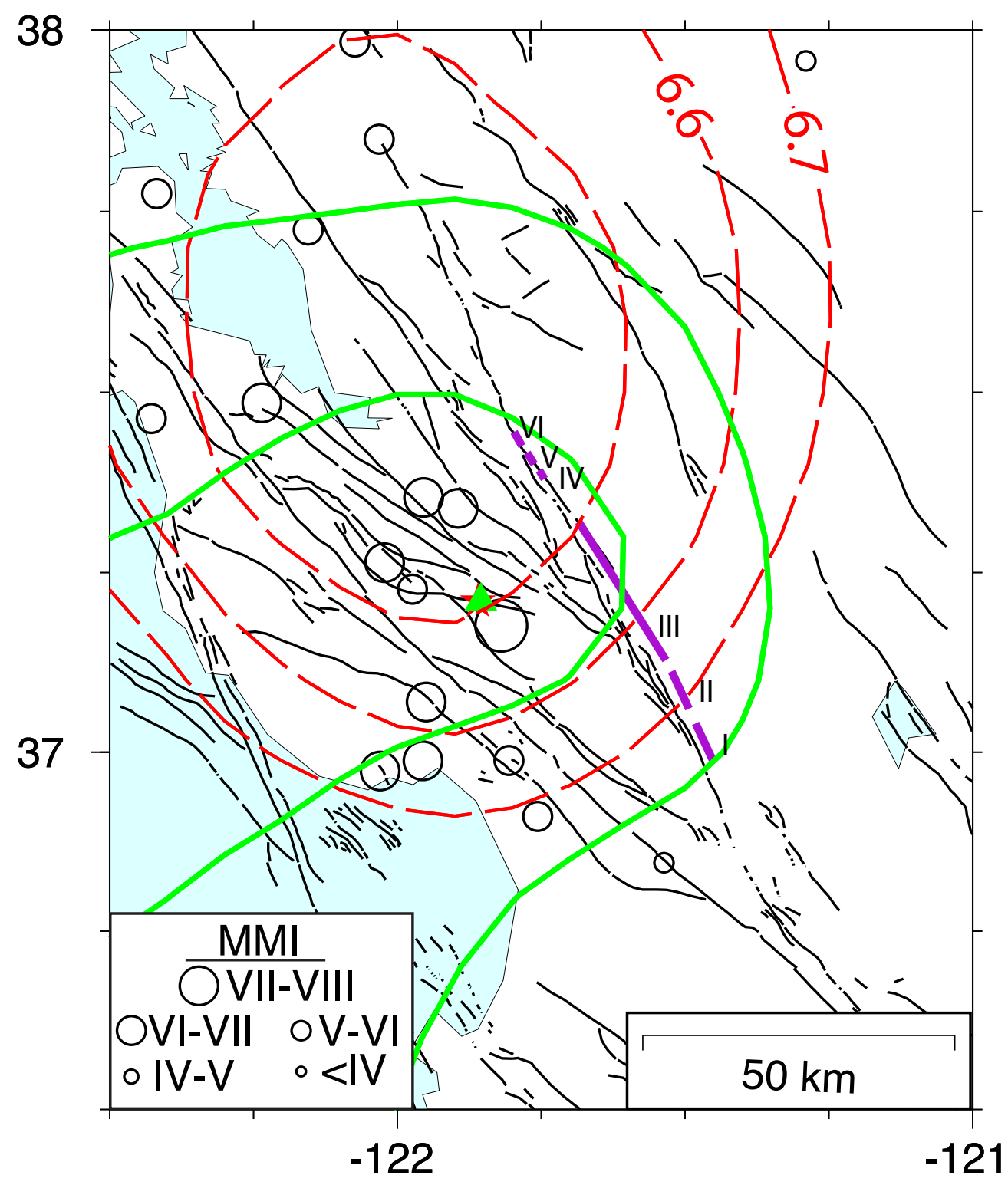

Figure 7. 8 October 1865 earthquake.

(MMI assignment-Site Correction) at 27 sites (some sites may be off the map) are shown as circles relative to Jenning's (1994) active faults (black lines). The contours of $M_{1}$ (dashed red lines) are the best estimates of $\mathbf{M}$ from the MMI data for assumed epicenters on that contour. The rms $\left[\mathrm{M}_{1}\right]$ contours corresponding to the $67 \%$ (innermost contour) and $95 \%$ confidence contour (outermost contour) for location (Bakun and Wentworth, 1999) are shown as solid green lines. The intensity center (Bakun, 1999) is a green triangle. Locations of Oppenheimer et al.'s (1990) zones I-VI on the central and southern Calaveras fault are shown as violet lines. 


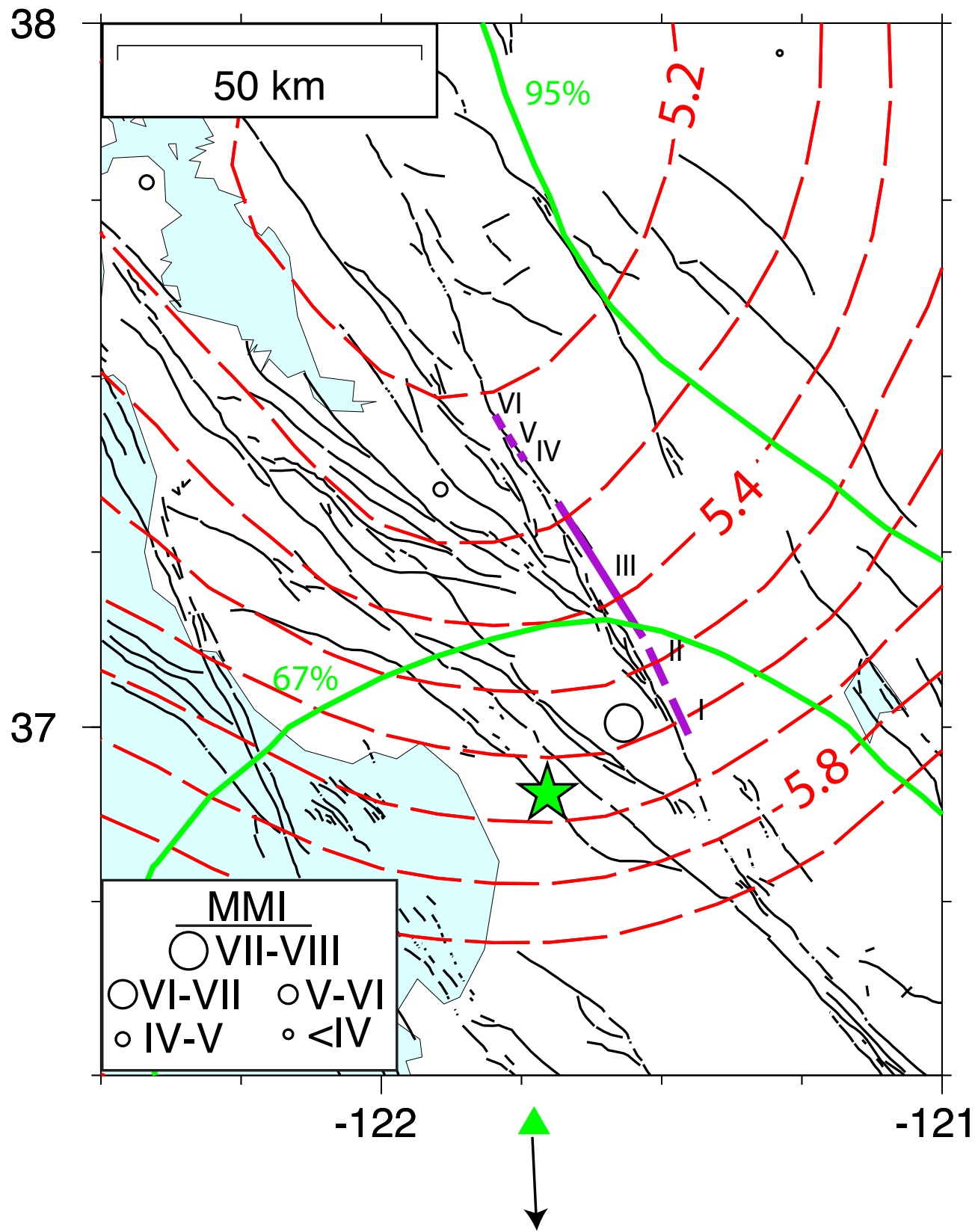

Figure 8. 26 March 1866 earthquake.

(MMI assignment-Site Correction) at 6 sites (some sites may be off the map) are shown as circles relative to Jenning's (1994) active faults (black lines). The contours of $M_{1}$ (dashed red lines) are the best estimates of $\mathbf{M}$ from the MMI data for assumed epicenters on that contour. The rms [M] contours corresponding to the $67 \%$ (innermost contour) and $95 \%$ confidence contour (outermost contour) for location (Bakun and Wentworth, 1999) are shown as solid green lines. The intensity center (Bakun, 1999) is a green triangle and is located off the map. The preferred location is the green star. Locations of Oppenheimer et al.'s (1990) zones I-VI on the central and southern Calaveras fault are shown as violet lines. 


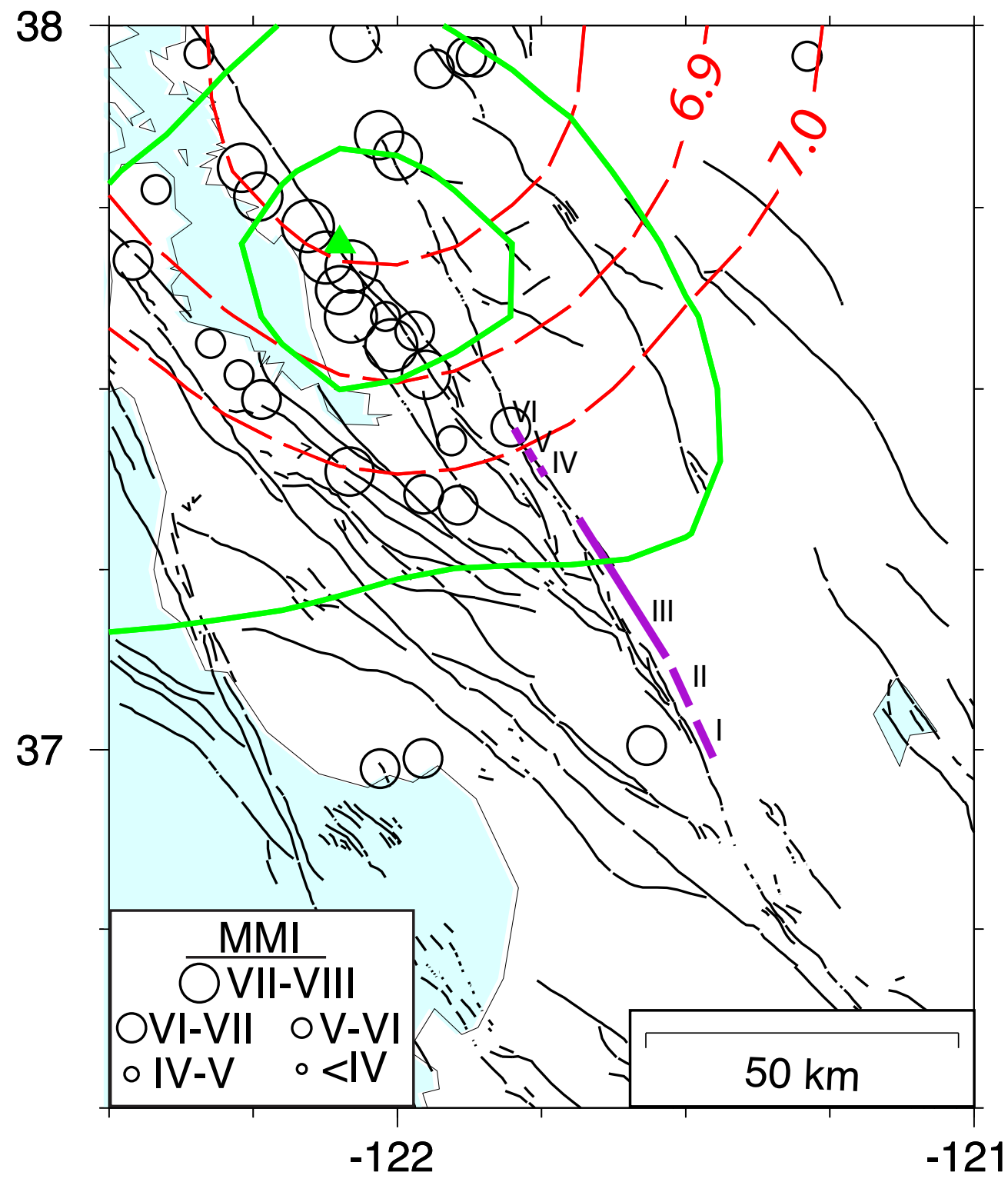

Figure 9a. 21 October 1868 earthquake.

(MMl assignment-Site Correction) at 70 sites (some sites may be off the map) are shown as circles relative to Jenning's (1994) active faults (black lines). The contours of $\mathrm{M}_{1}$ (dashed red lines) are the best estimates of $\mathbf{M}$ from the MMI data for assumed epicenters on that contour. The rms $\left[\mathrm{M}_{\mathrm{l}}\right]$ contours corresponding to the $67 \%$ (innermost contour) and $95 \%$ confidence contour (outermost contour) for location (Bakun and Wentworth, 1999) are shown as solid green lines. The intensity center (Bakun, 1999) is a green triangle. Locations of Oppenheimer et al.'s (1990) zones I-VI on the central and southern Calaveras fault are shown as violet lines. 


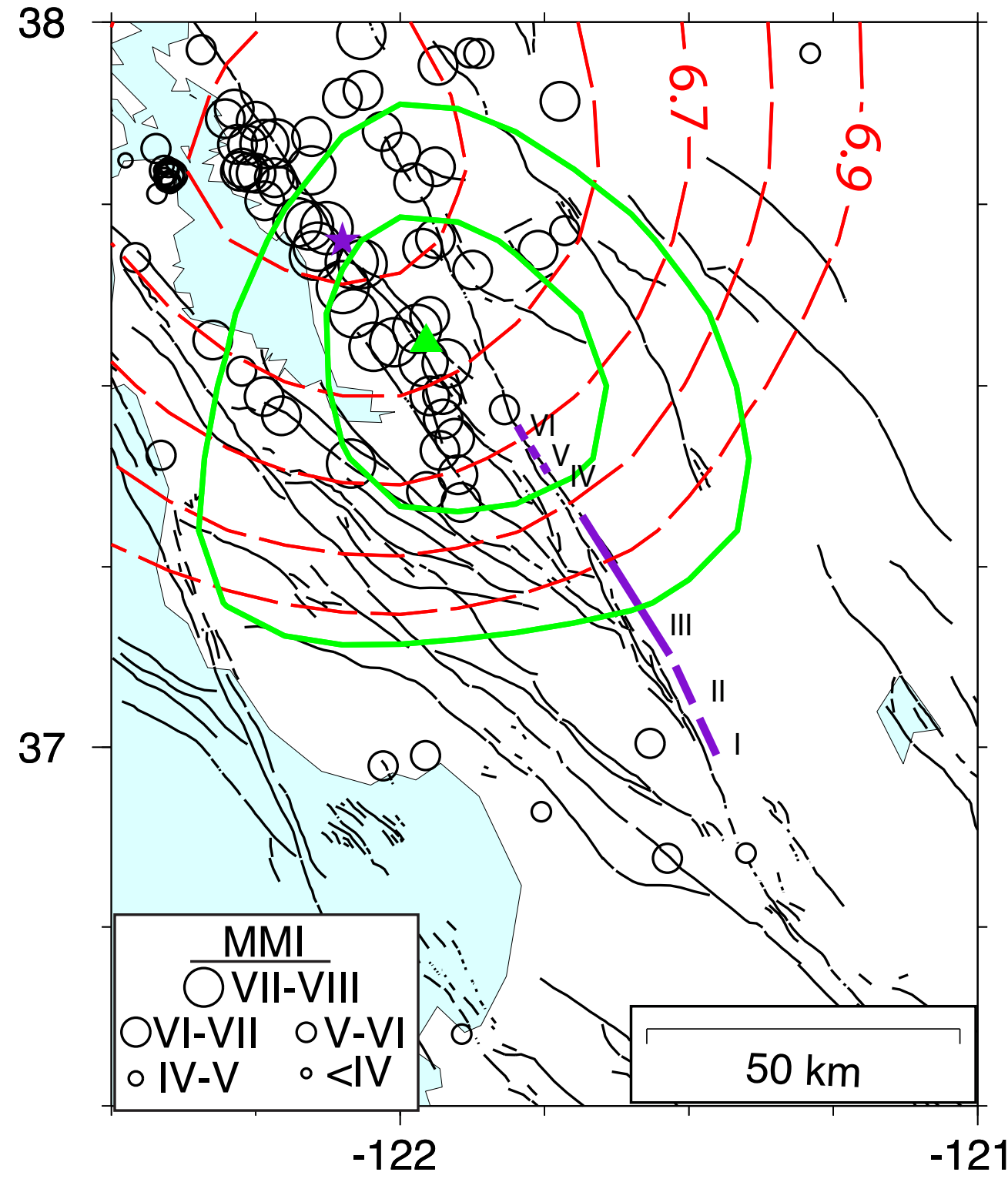

Figure 9b. 21 October 1868 earthquake.

(MMI assignment-Site Correction) at 133 sites (some sites may be off the map) assigned by J. Boatwright (personal communication, 2008) are shown as circles relative to Jenning's (1994) active faults (black lines). The contours of $M_{1}$ (dashed red lines) are the best estimates of $\mathbf{M}$ from the $\mathrm{MMI}$ data for assumed epicenters on that contour. The rms $\left[\mathrm{M}_{1}\right]$ contours corresponding to the $67 \%$ (innermost contour) and 95\% confidence contour (outermost contour) for location (Bakun and Wentworth, 1999) are shown as solid green lines. The intensity center (Bakun, 1999), a green triangle, is located on the Hayward fault about 20-25 km south of Bakun's (1999) intensity center (violet star). Locations of Oppenheimer et al.'s (1990) zones I-VI on the southern Calaveras fault are shown as violet lines. 


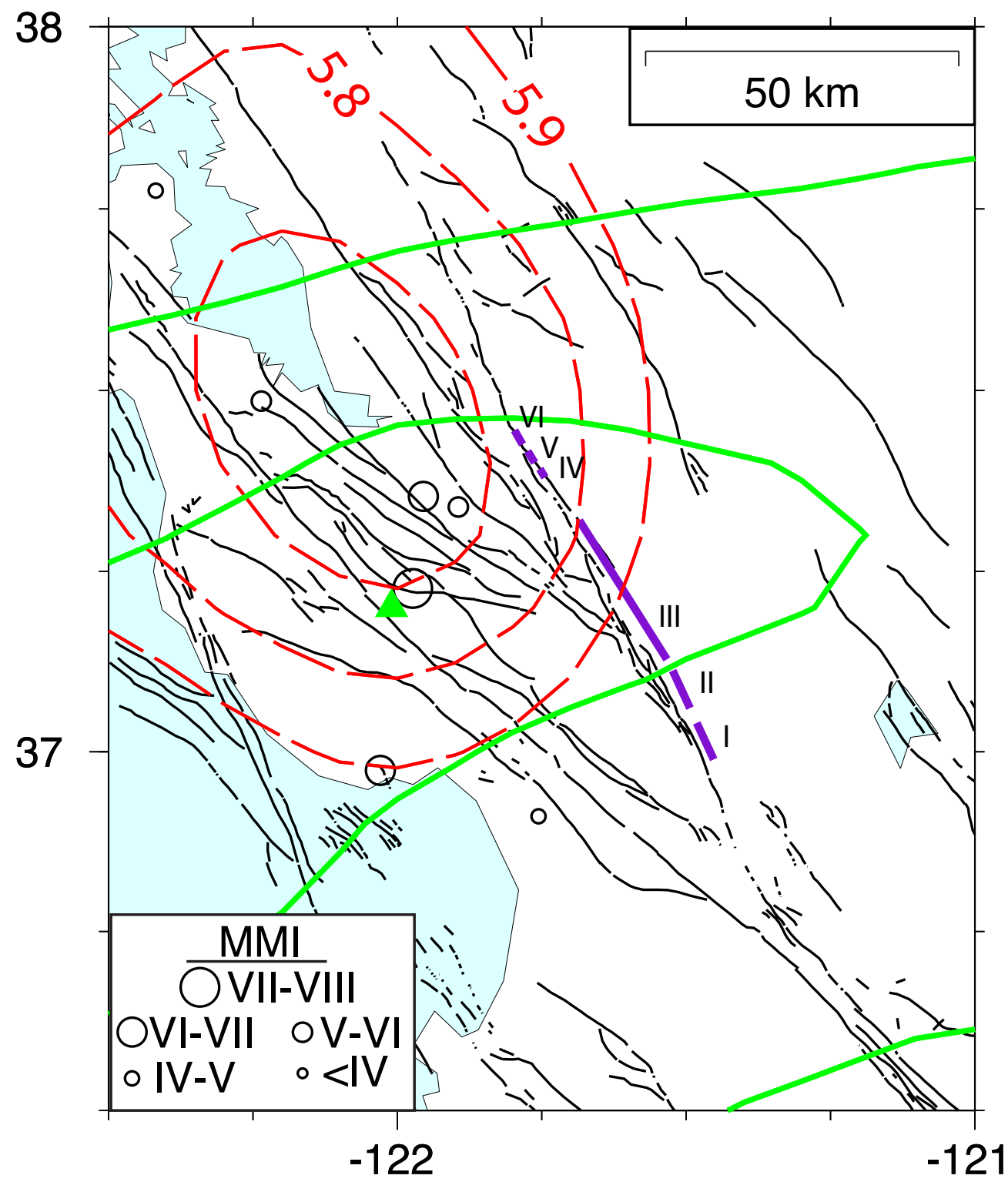

Figure 10. 17 February 1870 earthquake.

(MMI assignment-Site Correction) at 10 sites (some sites may be off the map) are shown as circles relative to Jenning's (1994) active faults (black lines). The contours of $\mathbf{M}_{1}$ (dashed red lines) are the best estimates of $\mathbf{M}$ from the MMI data for assumed epicenters on that contour. The rms $\left[\mathrm{M}_{\mathrm{l}}\right]$ contours corresponding to the $67 \%$ (innermost contour) and $95 \%$ confidence contour (outermost contour) for location (Bakun and Wentworth, 1999) are shown as solid green lines. The intensity center (Bakun, 1999) is a green triangle. Locations of Oppenheimer et al.'s (1990) zones I-VI on the central and southern Calaveras fault are shown as violet lines. 


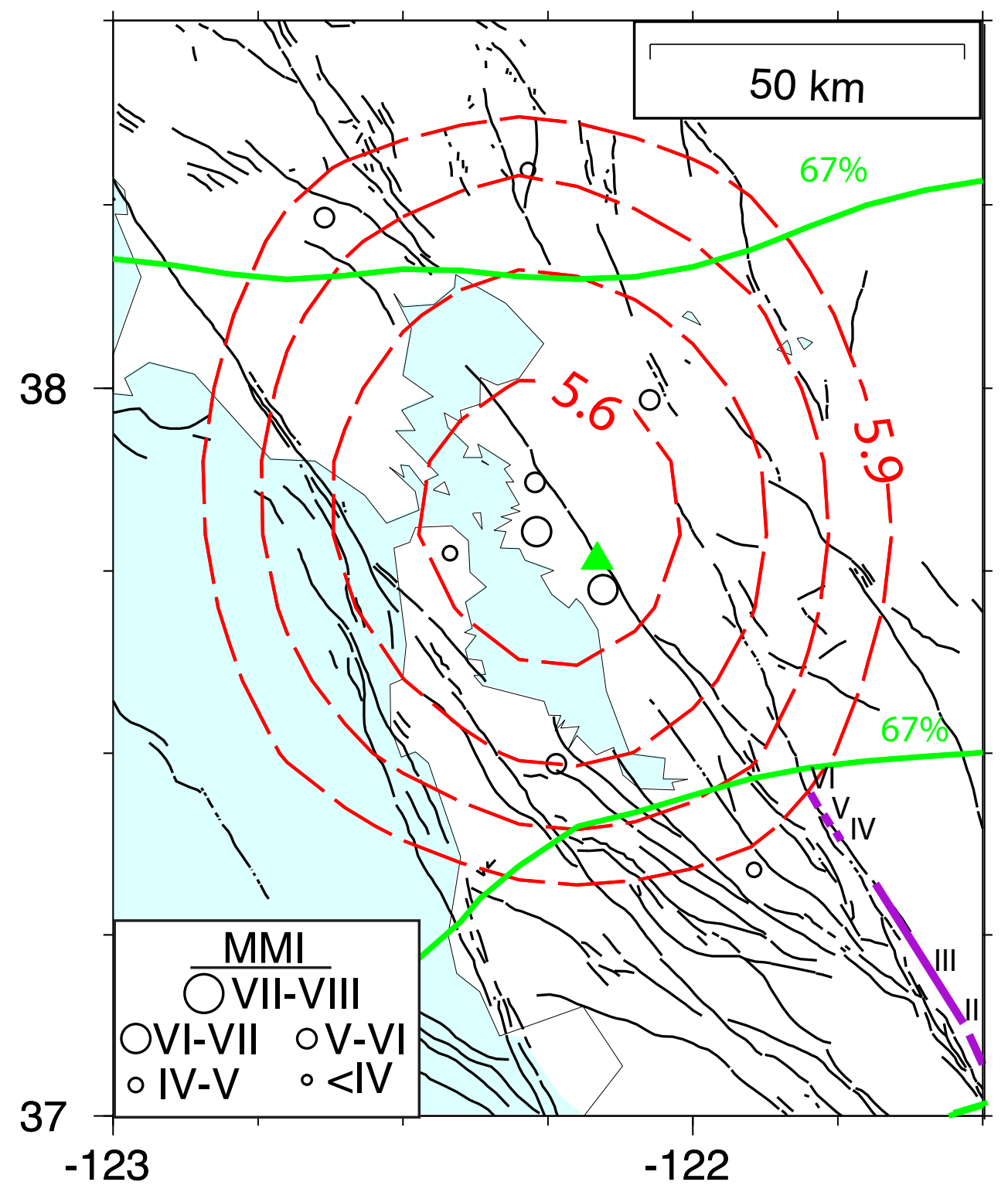

Figure 11. 2 April 1870 earthquake.

(MMl assignment-Site Correction) at 9 sites (some sites may be off the map) are shown as circles relative to Jenning's (1994) active faults (black lines). The contours of $\mathbf{M}_{1}$ (dashed red lines) are the best estimates of $\mathbf{M}$ from the MMI data for assumed epicenters on that contour. The rms $\left[\mathrm{M}_{1}\right]$ contours corresponding to the $67 \%$ (innermost contour) and $95 \%$ confidence contour (outermost contour) for location (Bakun and Wentworth, 1999) are shown as solid green lines. The intensity center (Bakun, 1999) is a green triangle. Locations of Oppenheimer et al.'s (1990) zones I-VI on the central and southern Calaveras fault are shown as violet lines. 


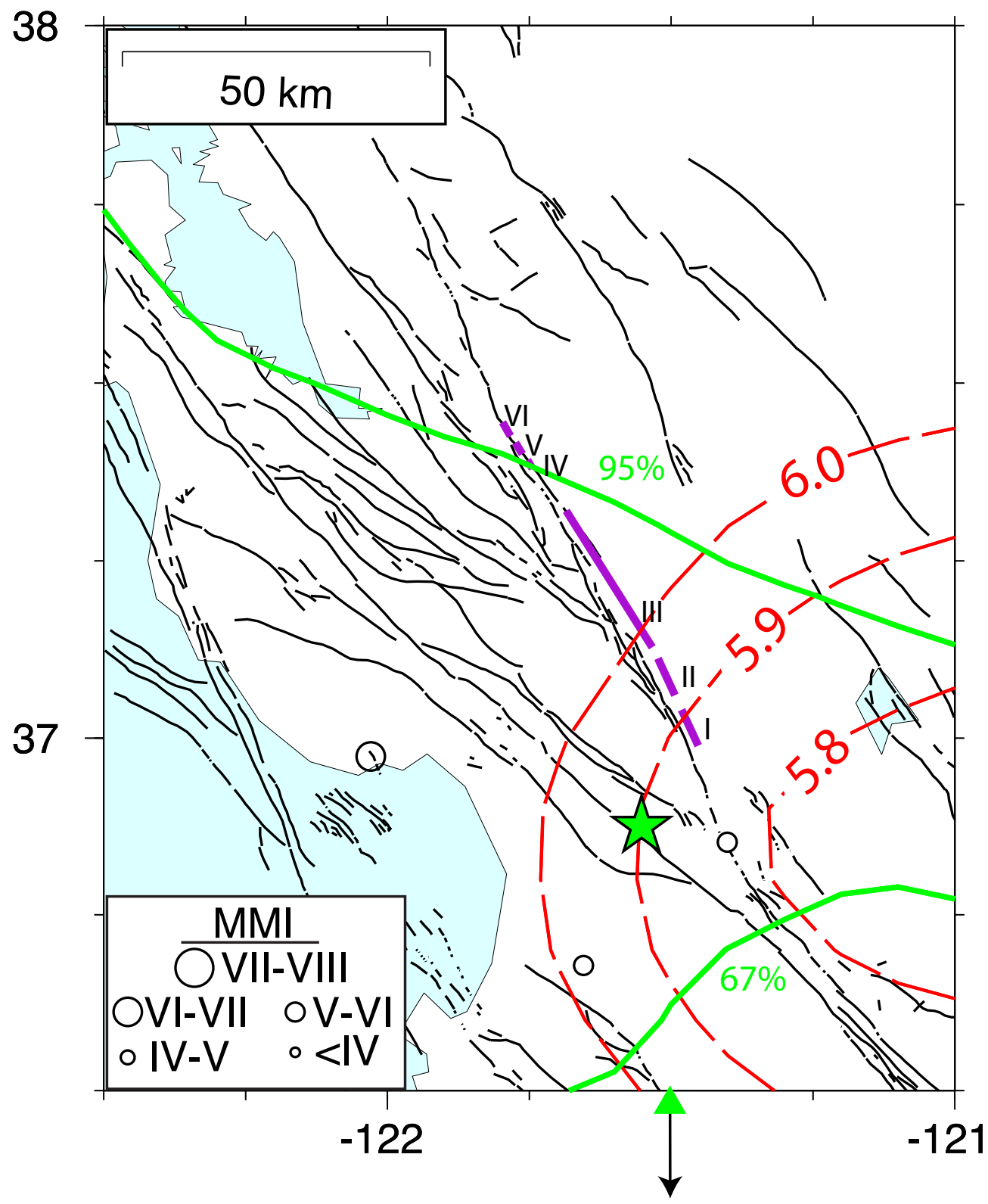

Figure 12. 6 March 1882 earthquake.

(MMI assignment-Site Correction) at 9 sites (some sites may be off the map) are shown as circles relative to Jenning's (1994) active faults (black lines). The contours of $\mathbf{M}_{1}$ (dashed red lines) are the best estimates of $\mathbf{M}$ from the MMI data for assumed epicenters on that contour. The rms $\left[\mathrm{M}_{1}\right]$ contours corresponding to the $67 \%$ (innermost contour) and $95 \%$ confidence contour (outermost contour) for location (Bakun and Wentworth, 1999) are shown as solid green lines. The intensity center (Bakun, 1999) is a green triangle. The preferred location is the green star. Locations of Oppenheimer et al.'s (1990) zones I-VI on the central and southern Calaveras fault are shown as violet lines. 


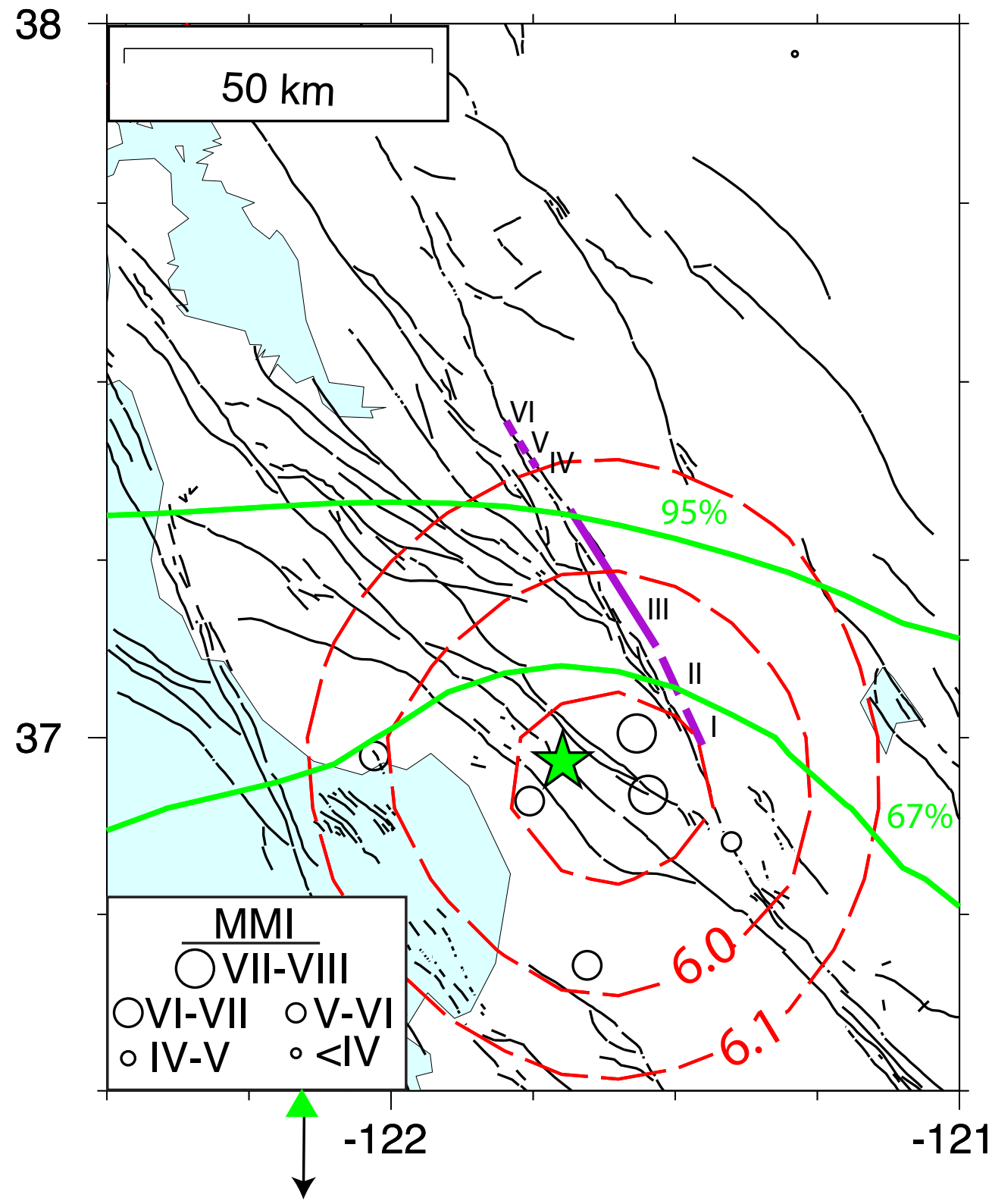

Figure 13. 30 March 1883 earthquake.

(MMI assignment-Site Correction) at 9 sites (some sites may be off the map) are shown as circles relative to Jenning's (1994) active faults (black lines). The contours of $\mathbf{M}_{1}$ (dashed red lines) are the best estimates of $\mathbf{M}$ from the MMI data for assumed epicenters on that contour. The rms $\left[\mathrm{M}_{1}\right]$ contours corresponding to the $67 \%$ (innermost contour) and $95 \%$ confidence contour (outermost contour) for location (Bakun and Wentworth, 1999) are shown as solid green lines. The intensity center (Bakun, 1999) is a green triangle. The preferred location is the green star. Locations of Oppenheimer et al.'s (1990) zones I-VI on the central and southern Calaveras fault are shown as violet lines. 
38

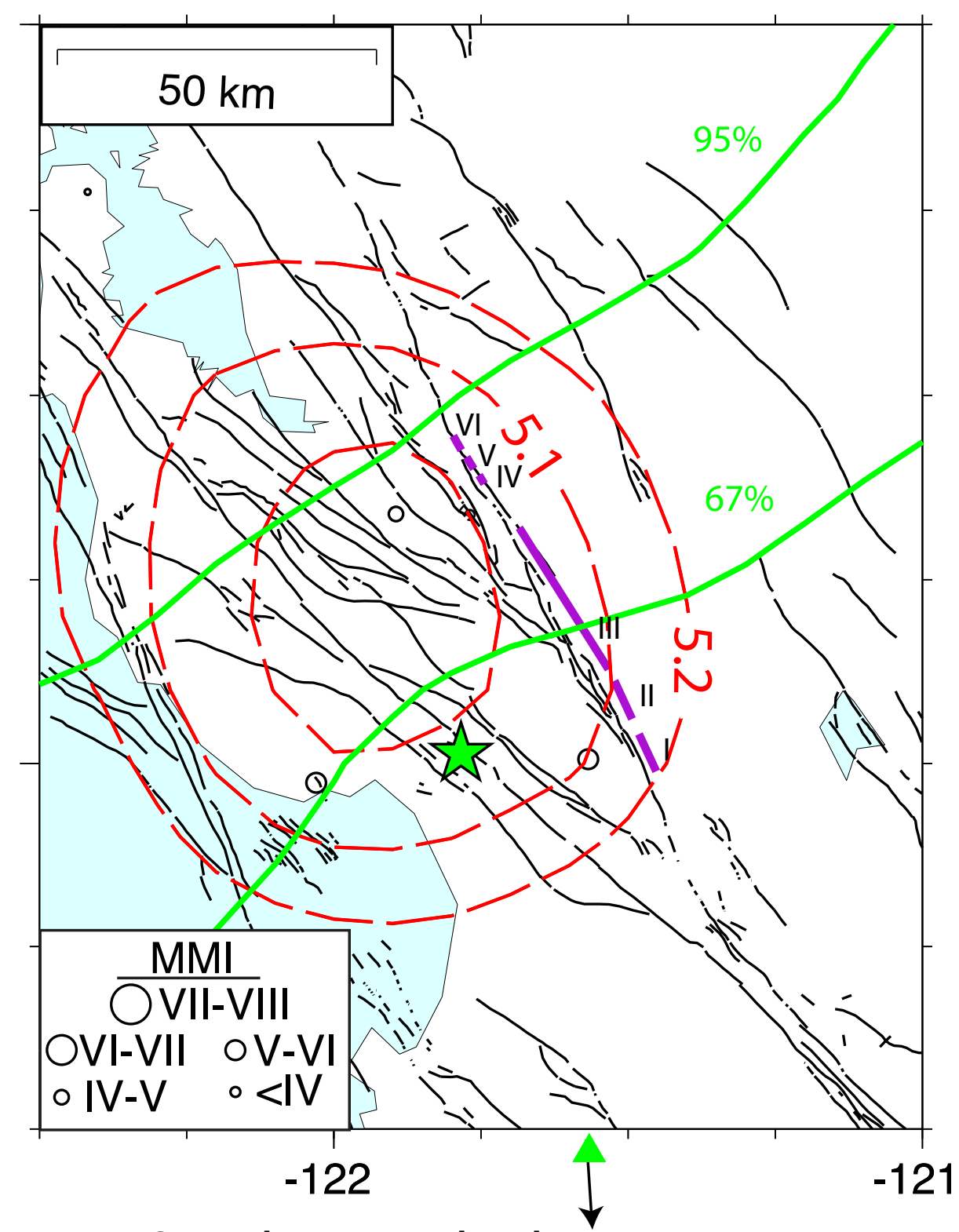

Figure 14. 17 September 1888 earthquake.

(MMI assignment-Site Correction) at 4 sites (some sites may be off the map) are shown as circles relative to Jenning's (1994) active faults (black lines). The contours of $\mathbf{M}_{1}$ (dashed red lines) are the best estimates of $\mathbf{M}$ from the MMI data for assumed epicenters on that contour. The rms [M] contours corresponding to the $67 \%$ (innermost contour) and $95 \%$ confidence contour (outermost contour) for location (Bakun and Wentworth, 1999) are shown as solid green lines. The intensity center (Bakun, 1999) is a green triangle. The preferred location is the green star. Locations of Oppenheimer et al.'s (1990) zones I-VI on the central and southern Calaveras fault are shown as violet lines. 


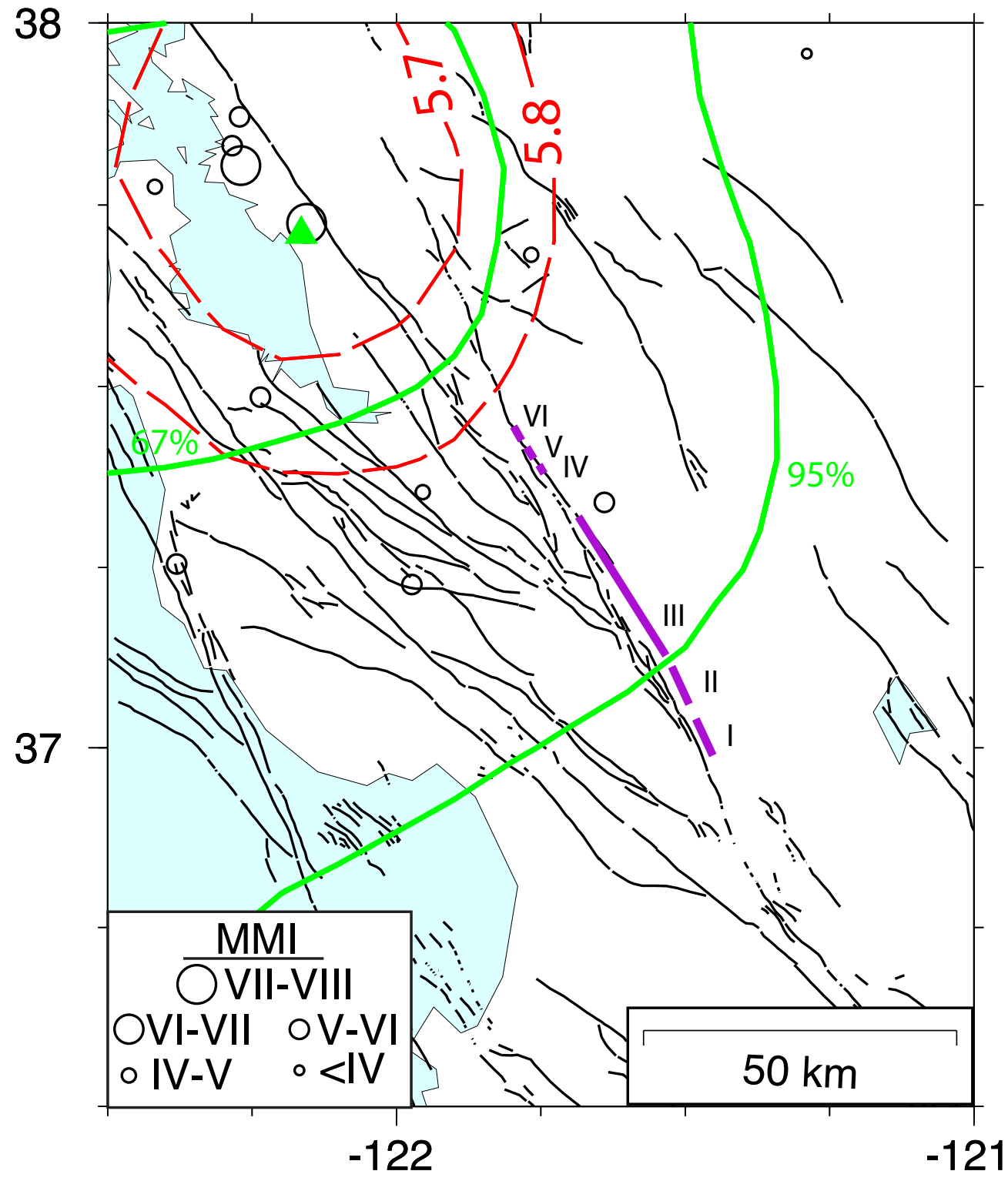

Figure 15. 31 July 1889 earthquake.

(MMl assignment-Site Correction) at 17 sites (some sites may be off the map) are shown as circles relative to Jenning's (1994) active faults (black lines). The contours of $\mathbf{M}_{1}$ (dashed red lines) are the best estimates of $\mathbf{M}$ from the MMI data for assumed epicenters on that contour. The rms $\left[\mathrm{M}_{\mathrm{l}}\right]$ contours corresponding to the $67 \%$ (innermost contour) and 95\% confidence contour (outermost contour) for location (Bakun and Wentworth, 1999) are shown as solid green lines. The intensity center (Bakun, 1999) is a green triangle. The preferred location is the intensity center. Locations of Oppenheimer et al.'s (1990) zones I-VI on the central and southern Calaveras fault are shown as violet lines. 


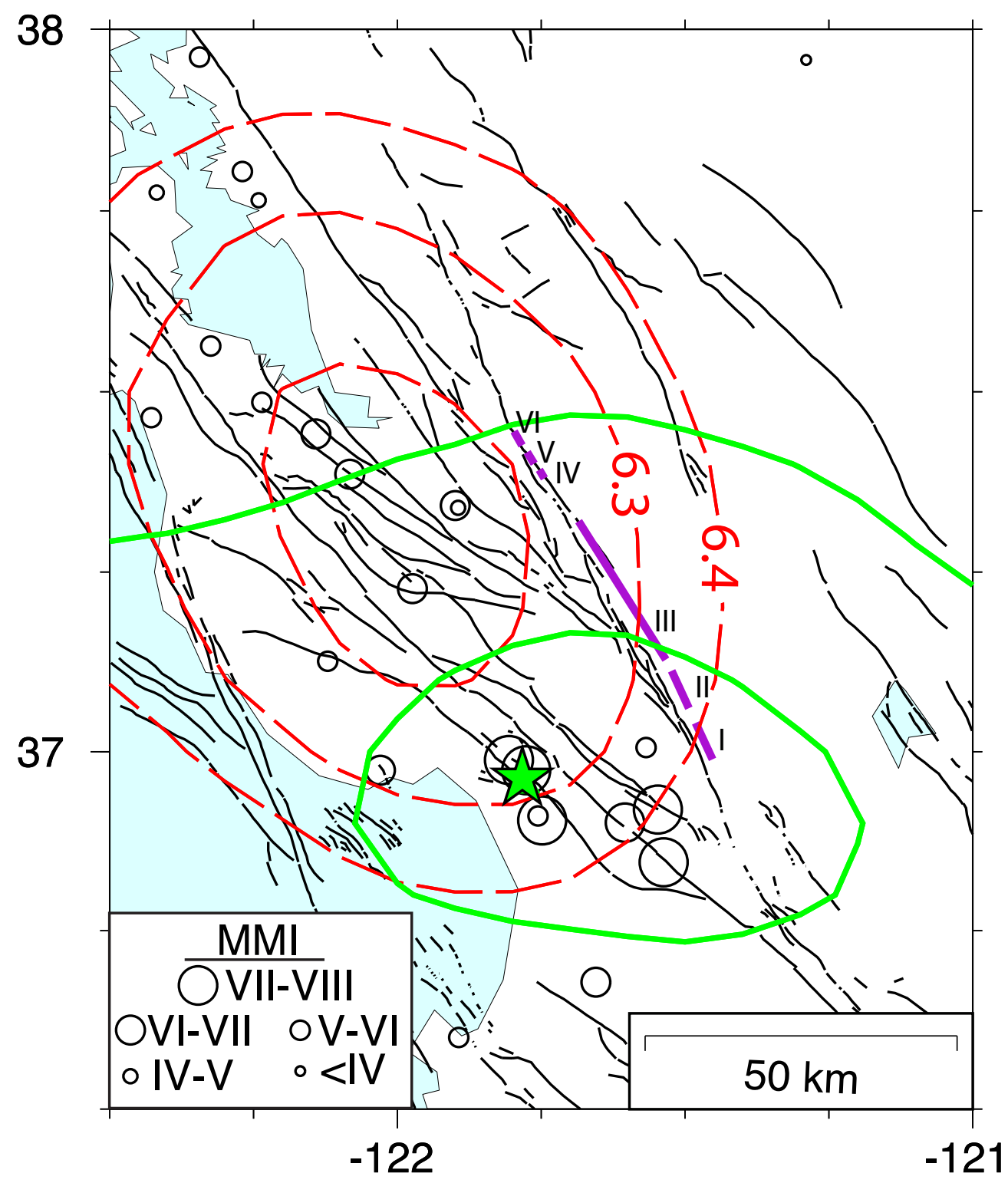

Figure 16. 24 April 1890 earthquake.

(MMI assignment-Site Correction) at 29 sites (some sites may be off the map) are shown as circles relative to Jenning's (1994) active faults (black lines). The contours of $\mathbf{M}_{1}$ (dashed red lines) are the best estimates of $\mathbf{M}$ from the MMI data for assumed epicenters on that contour. The rms $\left[\mathrm{M}_{\mathrm{l}}\right]$ contours corresponding to the $67 \%$ (innermost contour) and $95 \%$ confidence contour (outermost contour) for location (Bakun and Wentworth, 1999) are shown as solid green lines. The intensity center (Bakun, 1999) is a green triangle. The preferred location is the green star. Locations of Oppenheimer et al.'s (1990) zones I-VI on the central and southern Calaveras fault are shown as violet lines. 


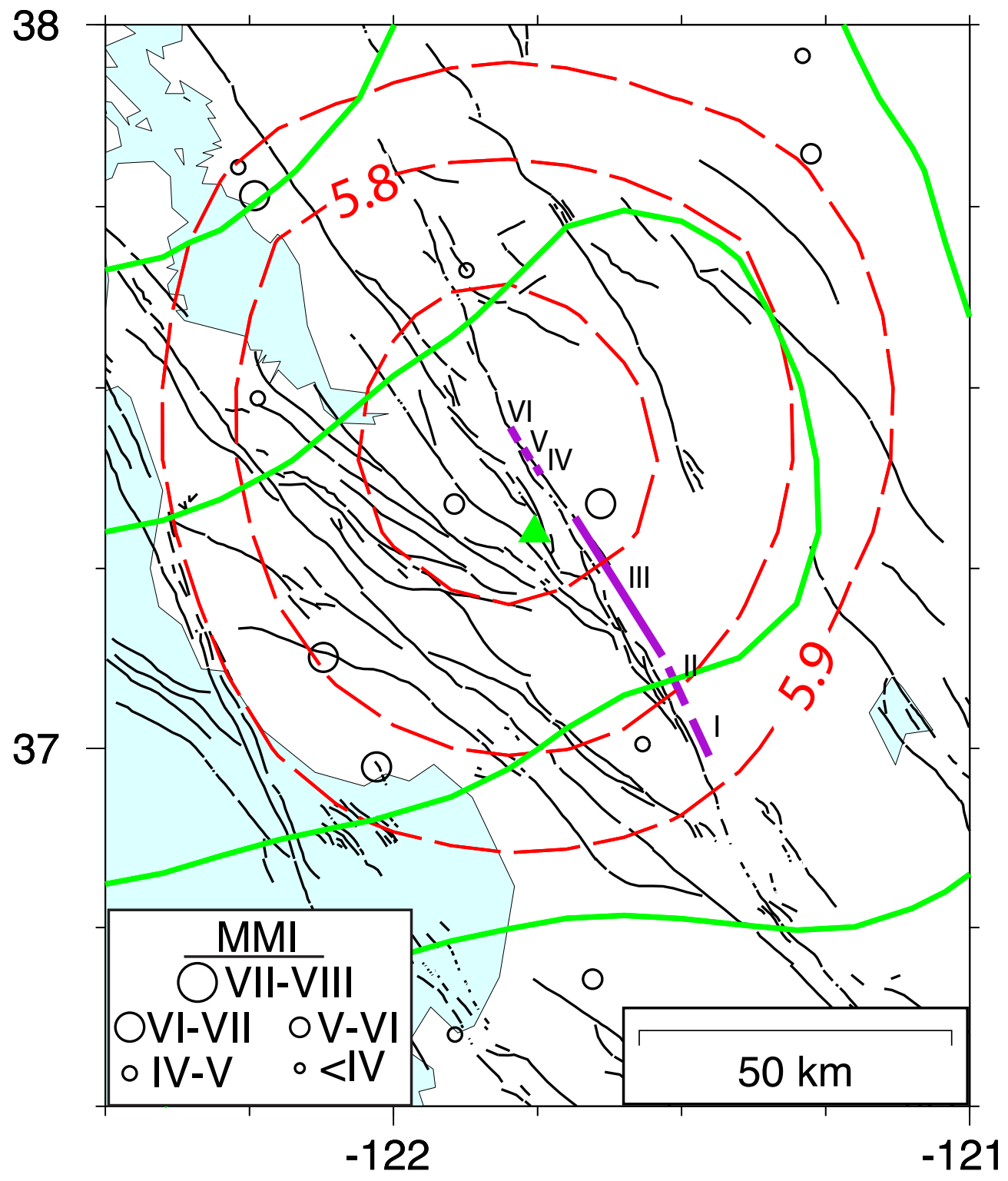

Figure 17. 2 January 1891 earthquake.

(MMI assignment-Site Correction) at 16 sites (some sites may be off the map) are shown as circles relative to Jenning's (1994) active faults (black lines). The contours of $\mathbf{M}_{1}$ (dashed red lines) are the best estimates of $\mathbf{M}$ from the MMI data for assumed epicenters on that contour. The rms $\left[\mathrm{M}_{1}\right]$ contours corresponding to the $67 \%$ (innermost contour) and $95 \%$ confidence contour (outermost contour) for location (Bakun and Wentworth, 1999) are shown as solid green lines. The intensity center (Bakun, 1999) is a green triangle. Locations of Oppenheimer et al.'s (1990) zones I-VI on the central and southern Calaveras fault are shown as violet lines. 


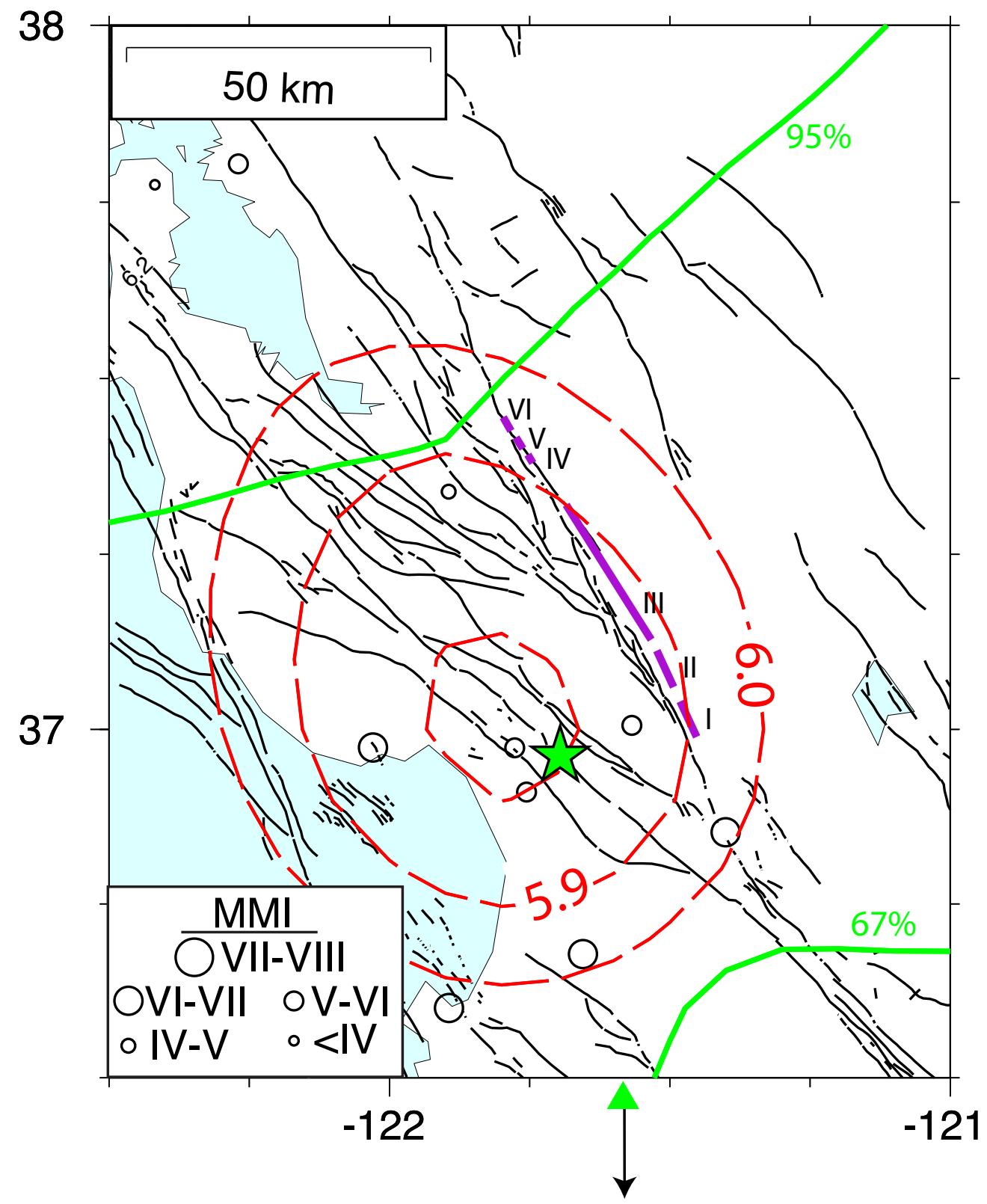

Figure 18. 13 November 1892 earthquake.

(MMl assignment-Site Correction) at 11 sites (some sites may be off the map) are shown as circles relative to Jenning's (1994) active faults (black lines). The contours of $\mathbf{M}_{1}$ (dashed red lines) are the best estimates of $\mathbf{M}$ from the MMI data for assumed epicenters on that contour. The rms $\left[\mathrm{M}_{\mathrm{l}}\right]$ contours corresponding to the $67 \%$ (innermost contour) and $95 \%$ confidence contour (outermost contour) for location (Bakun and Wentworth, 1999) are shown as solid green lines. The intensity center (Bakun, 1999) is a green triangle. The preferred location is the green star. Locations of Oppenheimer et al.'s (1990) zones I-VI on the central and southern Calaveras fault are shown as violet lines. 


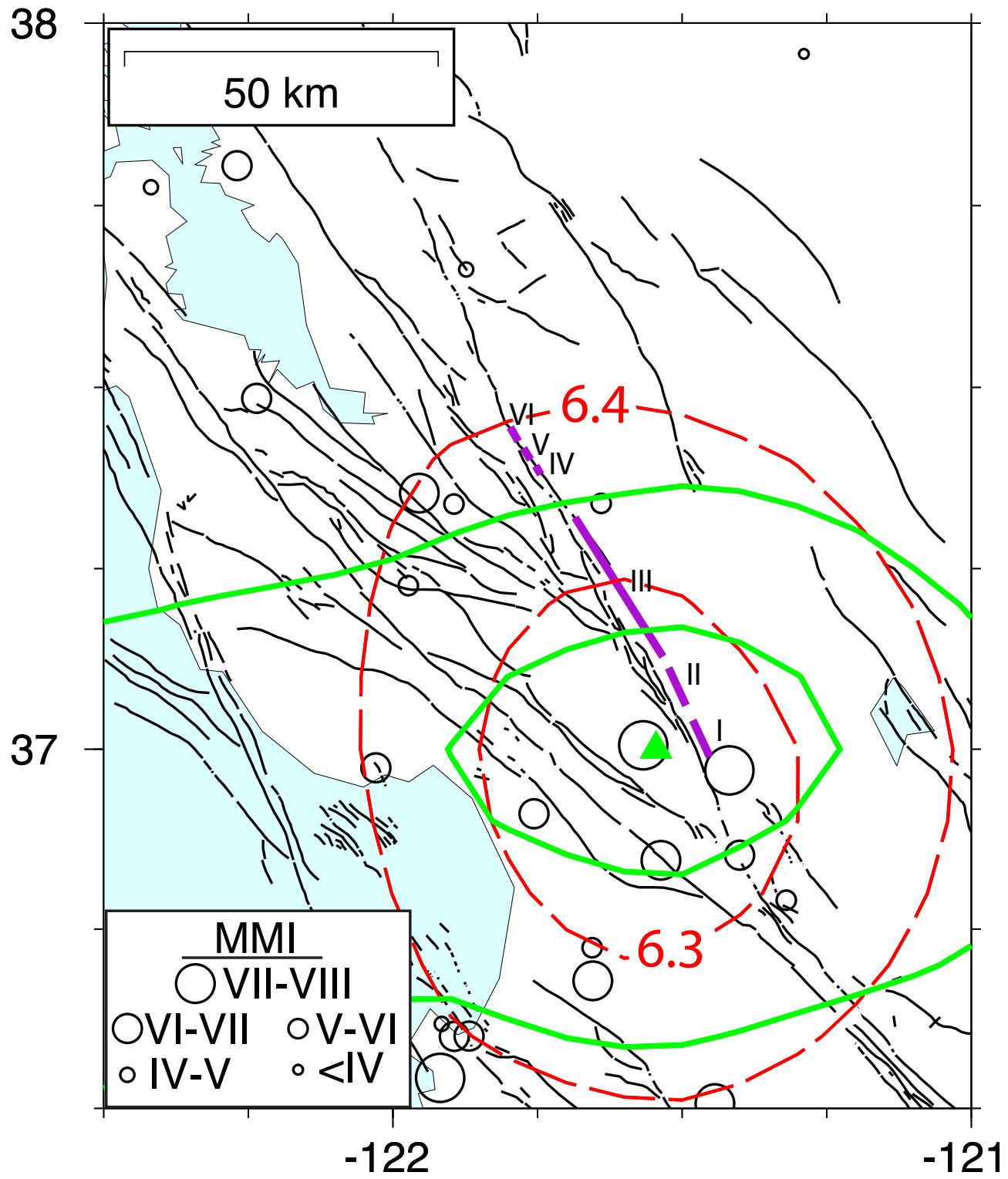

Figure 19. 20 June 1897 earthquake.

(MMI assignment-Site Correction) at 39 sites (some sites may be off the map) are shown as circles relative to Jenning's (1994) active faults (black lines). The contours of $\mathbf{M}_{1}$ (dashed red lines) are the best estimates of $\mathbf{M}$ from the MMI data for assumed epicenters on that contour. The rms [M] contours corresponding to the $67 \%$ (innermost contour) and $95 \%$ confidence contour (outermost contour) for location (Bakun and Wentworth, 1999) are shown as solid green lines. The intensity center (Bakun, 1999) is a green triangle. Locations of Oppenheimer et al.'s (1990) zones I-VI on the central and southern Calaveras fault are shown as violet lines. 


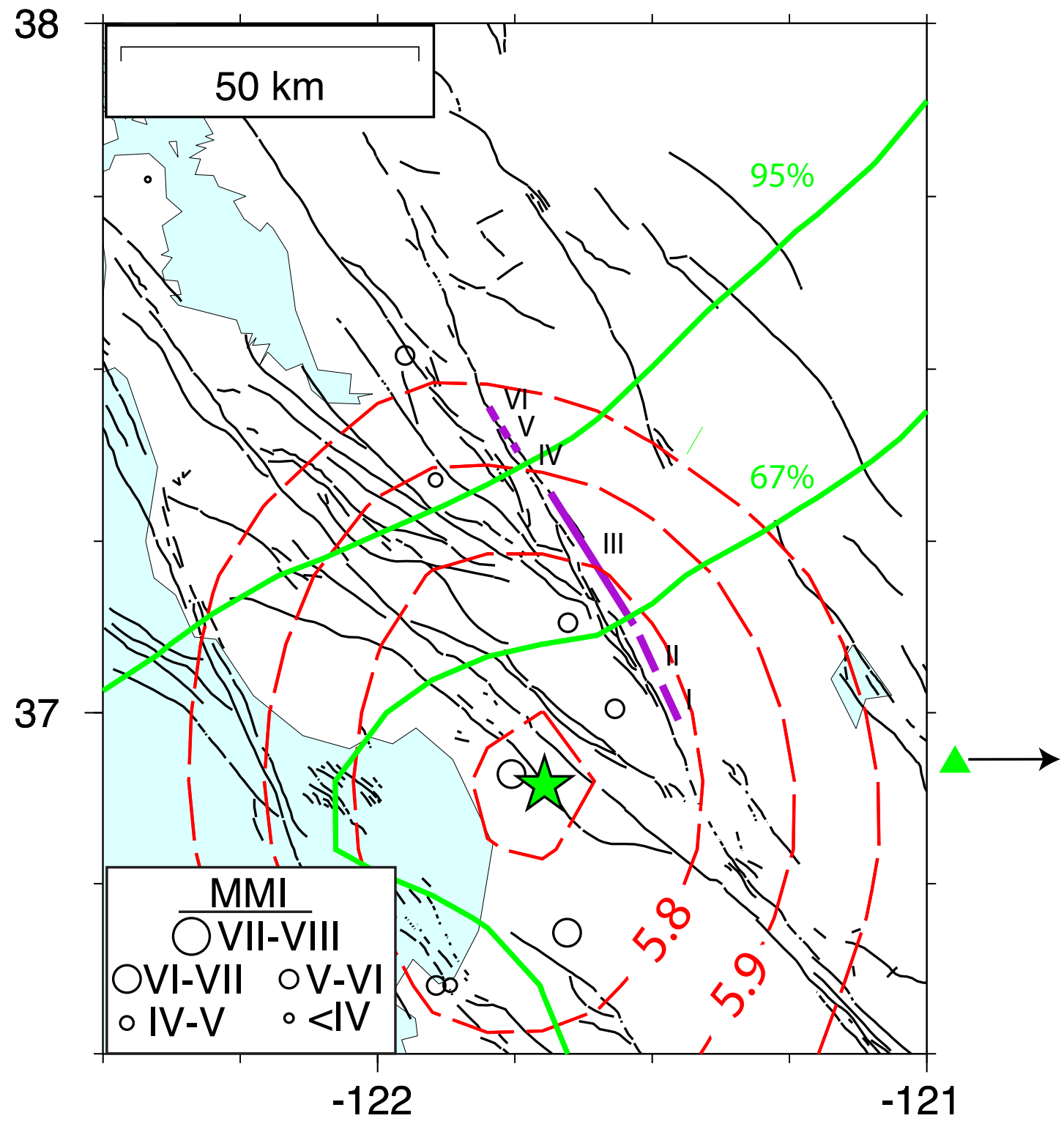

Figure 20. 6 July 1899 earthquake.

(MMI assignment-Site Correction) at 11 sites (some sites may be off the map) are shown as circles relative to Jenning's (1994) active faults (black lines). The contours of $\mathrm{M}_{1}$ (dashed red lines) are the best estimates of $\mathbf{M}$ from the MMI data for assumed epicenters on that contour. The rms $\left[\mathrm{M}_{\mathrm{l}}\right]$ contours corresponding to the $67 \%$ (innermost contour) and $95 \%$ confidence contour (outermost contour) for location (Bakun and Wentworth, 1999) are shown as solid green lines. The intensity center (Bakun, 1999) is a green triangle and id located off the map. The preferred location is the green star. Locations of Oppenheimer et al.'s (1990) zones I-VI on the central and southern Calaveras fault are shown as violet lines. 


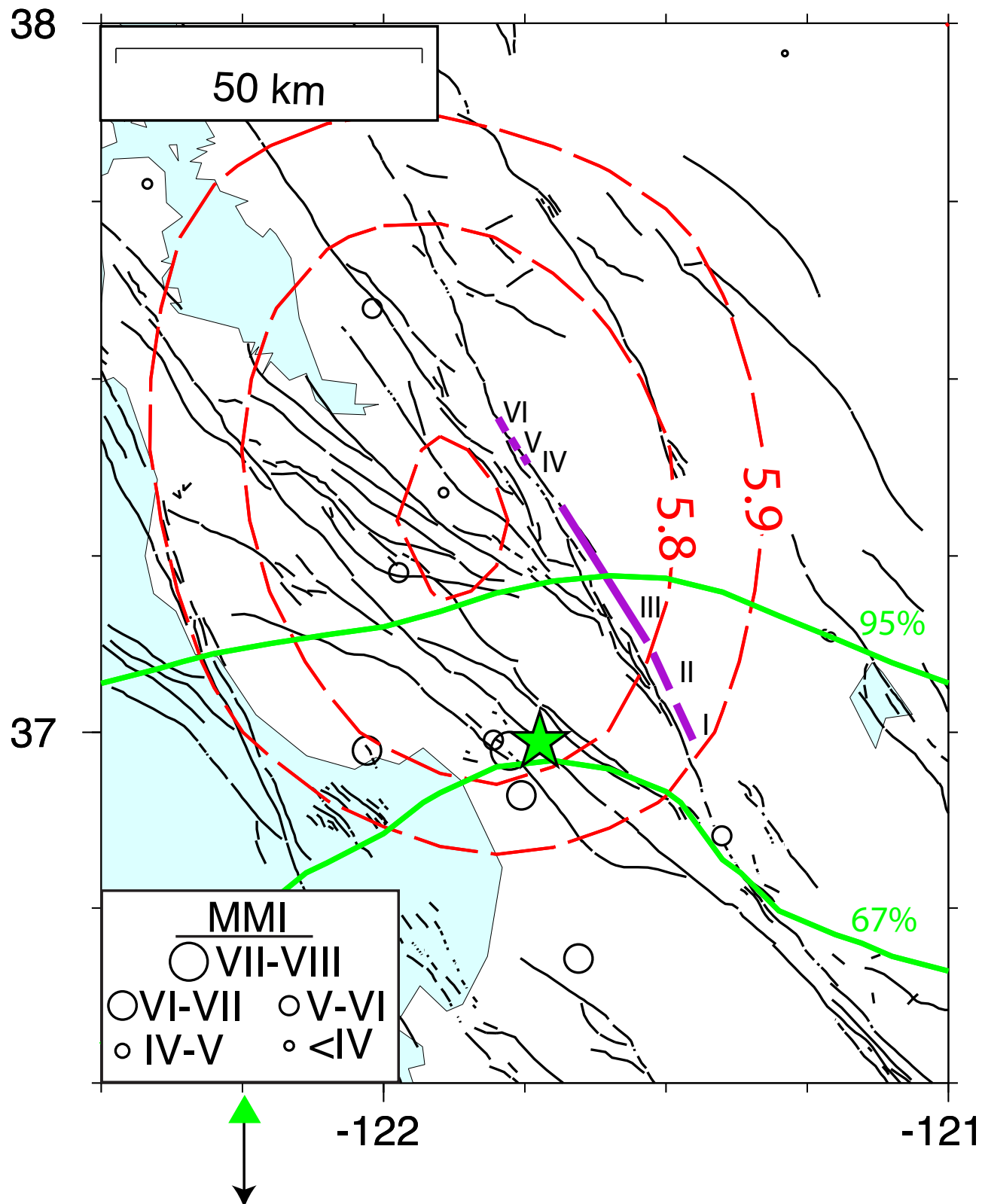

Figure 21. 30 April 1899 earthquake.

(MMI assignment-Site Correction) at 15 sites (some sites may be off the map) are shown as circles relative to Jenning's (1994) active faults (black lines). The contours of $\mathbf{M}_{1}$ (dashed red lines) are the best estimates of $\mathbf{M}$ from the MMI data for assumed epicenters on that contour. The rms $\left[\mathrm{M}_{l}\right]$ contours corresponding to the $67 \%$ (innermost contour) and $95 \%$ confidence contour (outermost contour) for location (Bakun and Wentworth, 1999) are shown as solid green lines. The intensity center (Bakun, 1999) is a green triangle. The preferred location is the green star. Locations of Oppenheimer et al.'s (1990) zones I-VI on the central and southern Calaveras fault are shown as violet lines. 


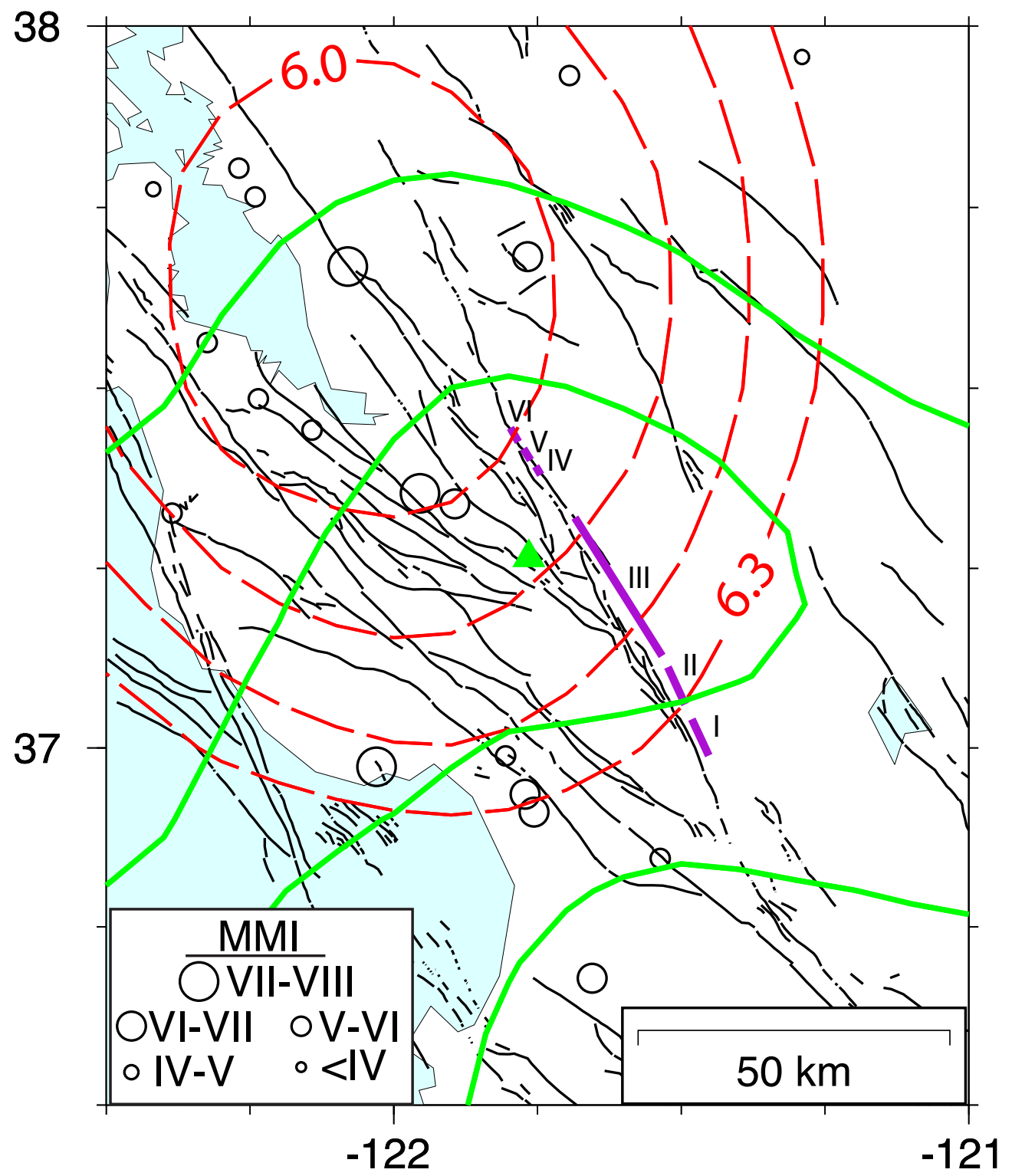

Figure 22. 11 June 1903 earthquake.

(MMl assignment-Site Correction) at 26 sites (some sites may be off the map) are shown as circles relative to Jenning's (1994) active faults (black lines). The contours of $M_{1}$ (dashed red lines) are the best estimates of $\mathbf{M}$ from the MMI data for assumed epicenters on that contour. The rms [M] contours corresponding to the $67 \%$ (innermost contour) and $95 \%$ confidence contour (outermost contour) for location (Bakun and Wentworth, 1999) are shown as solid green lines. The intensity center (Bakun, 1999) is a green triangle. Locations of Oppenheimer et al.'s (1990) zones I-VI on the central and southern Calaveras fault are shown as violet lines. 


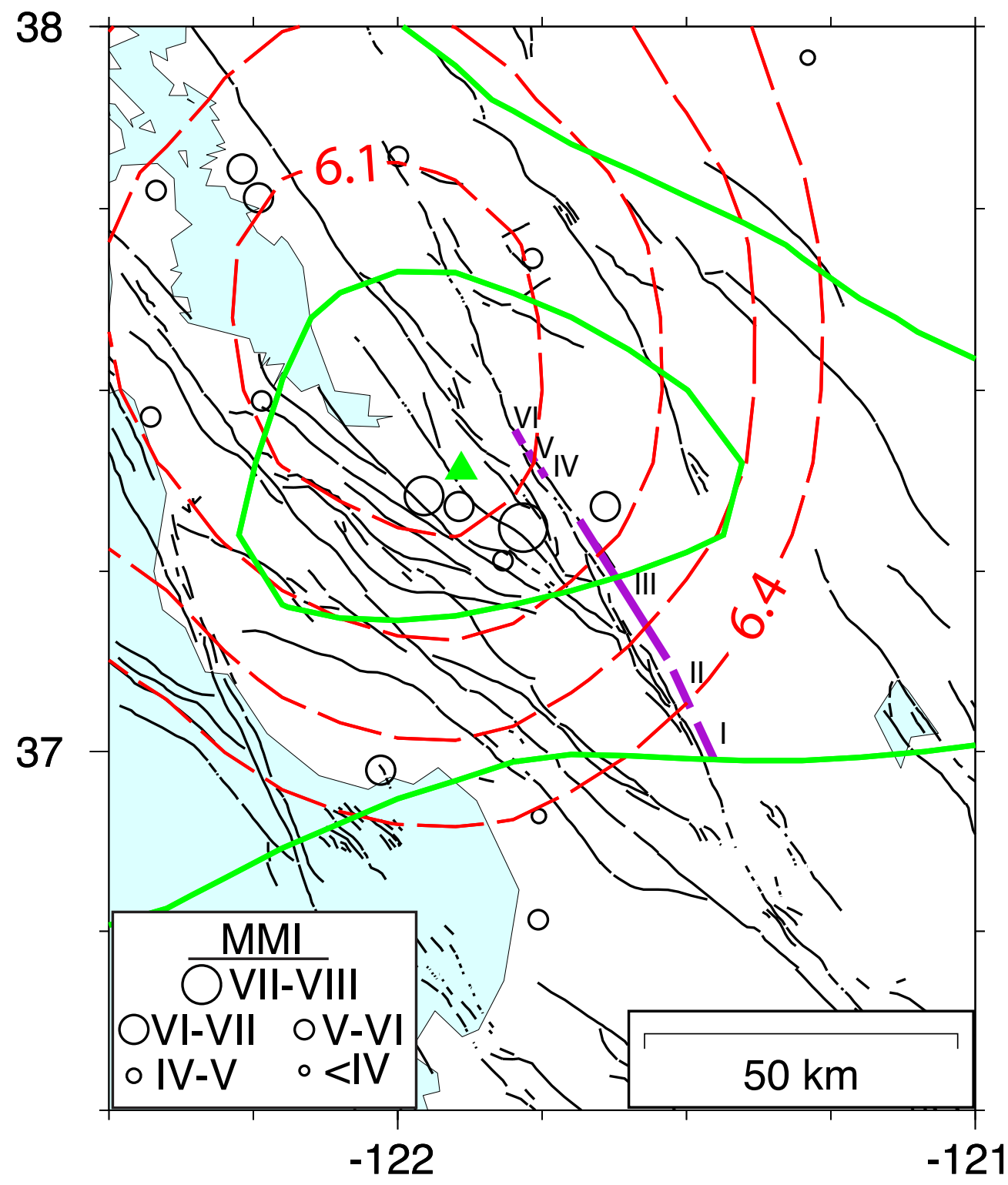

Figure 23. 3 August 1903 earthquake.

(MMl assignment-Site Correction) at 22 sites (some sites may be off the map) are shown as circles relative to Jenning's (1994) active faults (black lines). The contours of $\mathbf{M}_{1}$ (dashed red lines) are the best estimates of $\mathbf{M}$ from the MMI data for assumed epicenters on that contour. The rms $\left[\mathrm{M}_{1}\right]$ contours corresponding to the $67 \%$ (innermost contour) and $95 \%$ confidence contour (outermost contour) for location (Bakun and Wentworth, 1999) are shown as solid green lines. The intensity center (Bakun, 1999) is a green triangle. Locations of Oppenheimer et al.'s (1990) zones I-VI on the central and southern Calaveras fault are shown as violet lines. 


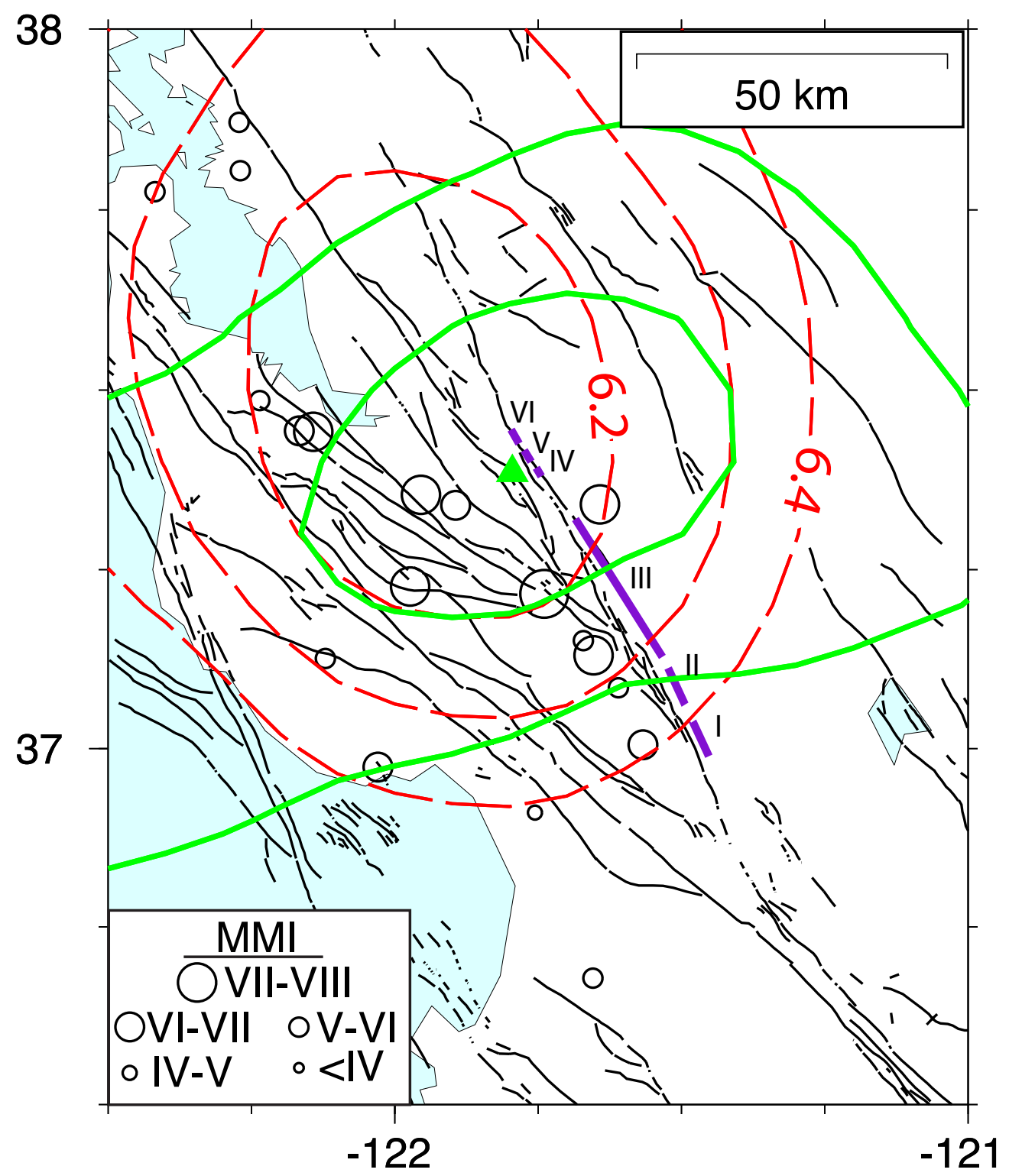

Figure 24. 1 July 1911 earthquake.

(MMI assignment-Site Correction) at 31 sites (some sites may be off the map) are shown as circles relative to Jenning's (1994) active faults (black lines). The contours of $M_{1}$ (dashed red lines) are the best estimates of $\mathbf{M}$ from the MMI data for assumed epicenters on that contour. The rms [M] contours corresponding to the $67 \%$ (innermost contour) and $95 \%$ confidence contour (outermost contour) for location (Bakun and Wentworth, 1999) are shown as solid green lines. The intensity center (Bakun, 1999) is a green triangle. Locations of Oppenheimer et al.'s (1990) zones I-VI on the central and southern Calaveras fault are shown as violet lines. 


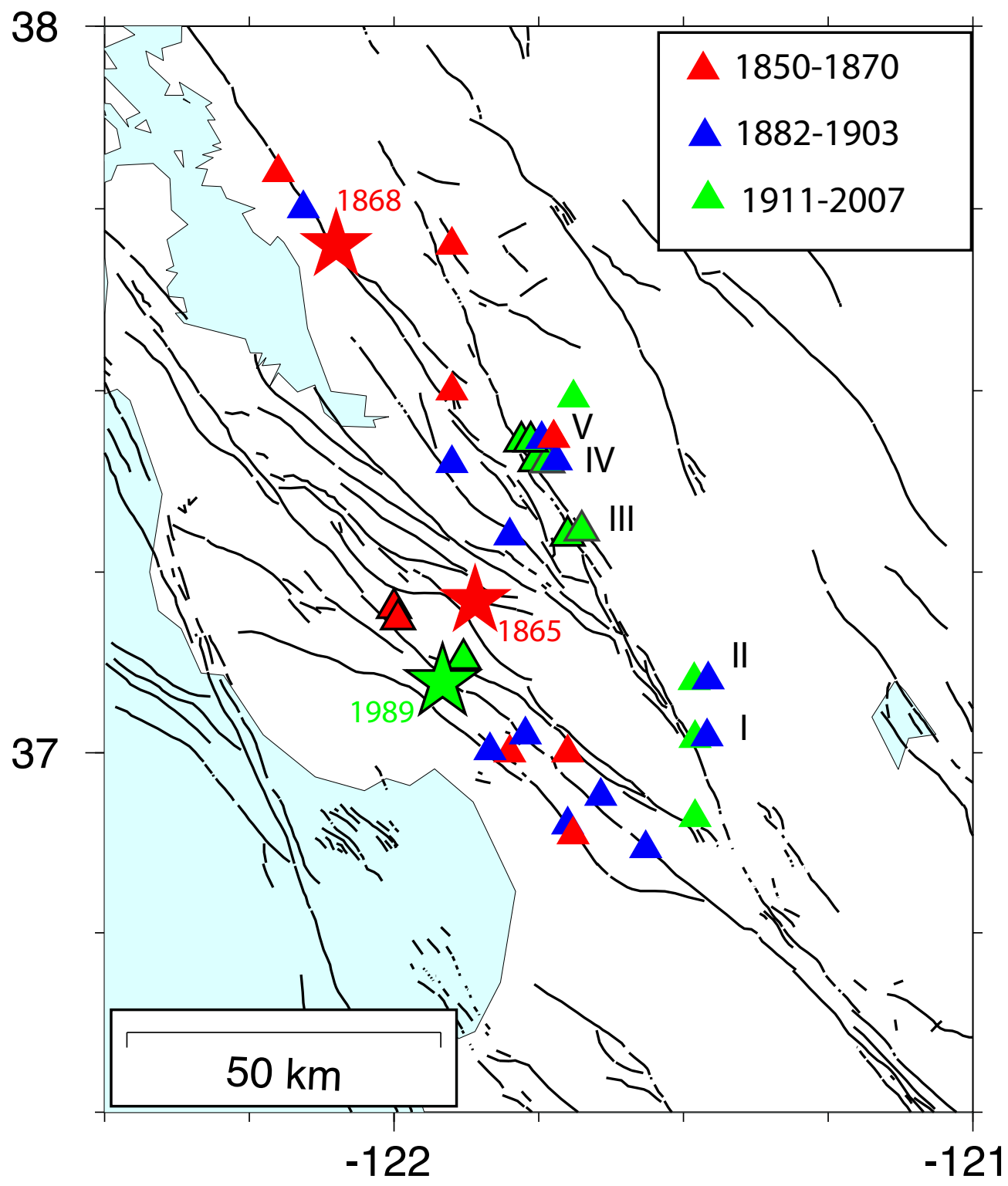

Figure 25. Preferred earthquake epicenters.

(Preferred locations in Table 1 are shown as triangles relative to Jenning's (1994) active faults (black lines). The M6.5 1865, M6.8 1868, and M6.9 1989 earthquakes are plotted as stars. I-VI are Oppenheimer et al.'s (1990) zones of recurring earthquakes on the Calaveras fault. 